\title{
CAMA
}

Centre for Applied Macroeconomic Analysis

\section{Financial Stability in Open Economies}

\section{CAMA Working Paper 71/2013 October 2013}

\section{Ippei Fujiwara}

Centre for Applied Macroeconomic Analysis (CAMA), ANU

Australia-Japan Research Centre, ANU

Crawford School of Public Policy, ANU

\section{Yuki Teranishi}

Centre for Applied Macroeconomic Analysis (CAMA), ANU

Faculty of Business and Commerce, Keio University

\begin{abstract}
Do financial frictions call for policy cooperation? This paper investigates the implications of financial frictions for monetary policy in the open economy. Welfare analysis shows that there are long-run gains which result from cooperation, but, dynamically, financial frictions per se do not require policy cooperation to improve global welfare over business cycles. In addition, inward-looking financial stability, namely eliminating inefficient fluctuations of loan premiums in its own country, is the optimal monetary policy in the open economy, irrespective of the existence of policy coordination.
\end{abstract}




\section{Keywords}

optimal monetary policy in open economy, financial market imperfections

\section{JEL Classification}

E50, F41

\section{Address for correspondence:}

(E) cama.admin@anu.edu.au

The Centre for Applied Macroeconomic Analysis in the Crawford School of Public Policy has been established to build strong links between professional macroeconomists. It provides a forum for quality macroeconomic research and discussion of policy issues between academia, government and the private sector.

The Crawford School of Public Policy is the Australian National University's public policy school, serving and influencing Australia, Asia and the Pacific through advanced policy research, graduate and executive education, and policy impact. 


\title{
Financial Stability in Open Economies*
}

\author{
Ippei Fujiwara $^{\dagger}$ \\ Yuki Teranishi ${ }^{\ddagger}$ \\ Australian National University Keio University
}

First Draft: June 2008; This Draft: October 2013

\begin{abstract}
Do financial frictions call for policy cooperation? This paper investigates the implications of financial frictions for monetary policy in the open economy. Welfare analysis shows that there are long-run gains which result from cooperation, but, dynamically, financial frictions per se do not require policy cooperation to improve global welfare over business cycles. In addition, inward-looking financial stability, namely eliminating inefficient fluctuations of loan premiums in its own country, is the optimal monetary policy in the open economy, irrespective of the existence of policy coordination.
\end{abstract}

${ }^{*}$ We have benefited from discussions with Kosuke Aoki, Pierpaolo Benigno, Larry Christiano, Giancarlo Corsetti, Richard Dennis, Bianca De Paoli, Marty Eichenbaum, Takeo Hoshi, Jinill Kim, Federico Mandelman, Tomoyuki Nakajima, Stefan Niemann, Maury Obstfeld, Bruce Preston, Lars Svensson, Cedric Tille, Mike Woodford, and seminar and conference participants at the University of Bonn, Hitotsubashi University, FRB Atlanta, Bank of Korea, University of Zurich, Victoria University of Wellington, Reserve Bank of New Zealand and Kyoto University. Fujiwara gratefully acknowledges financial support from the Murata Science Foundation.

${ }^{\dagger}$ Corresponding author. Centre for Applied Macroeconomic Analysis, Australia-Japan Research Centre and Crawford School of Public Policy, Lennox Crossing, Building \#132, The Australian National University, Canberra ACT 0200, Australia. E-mail: ippei.fujiwara@anu.edu.au

$\ddagger$ Faculty of Business and Commerce, Keio University, 2-15-45 Mita, Minato-ku, Tokyo 108-8345, Japan. E-mail: yukitera@fbc.keio.ac.jp 


\section{JEL Classification: E50; F41}

Keywords: $\quad$ optimal monetary policy in open economy; financial market imperfections

\section{Introduction}

The recent global financial crisis has renewed interest in the potential of policy cooperation. In order for the global economy to recover, the need for policy cooperation is now a topic of discussion for leaders in major policy institutions. ${ }^{1}$ To name a few, Dr. John Lipsky, Acting Managing Director of the IMF, stated on 21 June 2011, "A second success is the remarkable increase in global policy cooperation that has taken place in the wake of the 2008-09 global financial crisis. When the world last faced such grave danger - during the Great Depression - countries acted in their own, perceived self-interest with beggar-thy-neighbor policies that in fact deepened the downturn. This time, countries acted together to tackle the crisis." In addition, Mr. Jörg Asmussen, Member of the Executive Board of the ECB, said on 23 June 2013, "Alongside domestic shocks, countries are now more exposed than in the past to external financial shocks and global shocks to confidence. Keeping one's 'house in order' is no longer sufficient to fully insulate domestic economy from these shocks."

Academic studies, however, do not usually emphasize the importance of cooperation in stabilization policies. ${ }^{2}$ Corsetti, Dedola, and Leduc (2010) summarize the nature of the optimal monetary policy in the open economy and conclude that, "In welfare terms, the gains from cooperation are close to zero. Indeed, the literature has presented numerical assessments of the benchmark model under the complete markets that do not generate appreciable quantitative welfare gains from coordinating policies, relative to optimal stabilization pursued by independent policy makers (engaging in strategic manipulation of terms of trade)." ${ }^{3}$ The literature tends to recommend that policy makers

\footnotetext{
${ }^{1}$ All quoted positions are those at the time of the speech.

${ }^{2}$ Another area where gains from policy cooperation is the focus of intense discussion is financial regulation. Policy cooperation for financial regulation is, however, beyond the scope of this paper.

${ }^{3}$ Gains can arise from cooperation, depending on the export price setting or shocks. Clarida, Gali, and
} 
focus on domestic issues. Inward-looking policy solely aimed at the stabilization of home variables, namely keeping one's house in order, is thought to be optimal even under the integrated world economy. ${ }^{4}$ In particular, Woodford (2007) reviews "the consequences of global integration of financial markets, final goods markets, and factor markets for the form of each of these parts of the monetary transmission mechanism," and concludes that "globalization, even of a much more thorough sort than has yet occurred, is unlikely to weaken the ability of national central banks to control the dynamics of inflation." 5 Thus, "it will continue to be appropriate to hold national central banks responsible for domestic inflation outcomes." Also, from the policy sphere, Governor Elizabeth Duke of the Federal Reserve System warned on 20 July 2012 that "while central banks may benefit from coordination and cooperation, taking the same policy stance at the same time typically will not be the best choice for all central banks. Accordingly, it is imperative for each central bank to have monetary policy tools to appropriately address domestic objectives independent of the actions of other central banks."

What caused these divergent views on policy prescriptions during the global financial crisis? Perri and Quadrini (2011) emphasize the importance of financial market imperfec-

Gertler (2002) and Benigno and Benigno (2003) show that there is no gain from policy cooperation with producer currency pricing. When the economy is facing a markup shock, however, Benigno and Benigno (2006) find gains from cooperation even with producer currency pricing. However, inward-looking policy can still replicate the allocations under cooperation. On the other hand, Devereux and Engel (2003) show that there are gains from cooperation with local currency pricing. For a comprehensive summary of the optimal monetary policy in an open economy, see Corsetti, Dedola, and Leduc (2010).

${ }^{4}$ Note that inward-looking policy does not necessarily imply equivalence in allocations between cooperation and noncooperation.

${ }^{5}$ Improvement of the terms of trade raises the unit price of net export, while it decreases the quantity of net export by shifting demand from domestically produced goods to import goods. Cole and Obstfeld (1991) show that those two effects cancel each other completely, when the intratemporal elasticity of substitution between home and foreign goods is one. Under the assumption of the log utility, the terms of trade effect provides perfect insurance. There is no difference between costless trades and no trade at all. This irrelevance result indicates that effects from financial globalization should not be very large, according to Woodford (2007). 
tions in explaining the unprecedented degree of synchronization of business cycles across different countries during the recent global financial crisis. In this paper, we tackle this problem by investigating the implications from financial market imperfections on monetary policy in an open economy. The questions we raise in this paper are as follows. Is there any specific implication from financial market imperfections on policy cooperation? Do financial frictions call for policy cooperation? Can inward-looking policy replicate the allocations under cooperation even in the presence of financial market imperfections?

In order to answer to these questions, we extend the standard new open economy macroeconomics (NOEM) model a la Clarida, Gali, and Gertler (2002) or Benigno and Benigno (2003, 2006), to incorporate an imperfectly competitive banking sector as examined in Kobayashi (2008), Teranishi (2008), Mandelman (2010, 2011), and Fujiwara and Teranishi (2011). The banking sector of our model has three features: cost channel; monopoly power by banks over loan rate settings; staggered loan contracts. Loan demands stem from working capital loans. Firms need to borrow working capital from private banks in advance to finance wage bills. Barth and Ramey (2002) and Ravenna and Walsh (2006) empirically demonstrate the importance of this cost channel in the monetary policy transmission in the U.S. Each bank is assumed to be in a long-term relationship with each intermediate-goods producing firm. Thus, banks have monopoly power over loan rate settings. Gropp and Kashyap (2010), van Leuvensteijn, Sorensen, Bikker, and van Rixtel (2013) and Mandelman (2010, 2011) emphasize the importance of bank competitions on loan rate settings. Finally, dynamic frictions in the financial market are captured by staggered loan contracts, that follow Calvo (1983) - Yun (1996) framework.

The stickiness in the loan rate contracts is reported by many studies, as Slovin and Sushka (1983) and Berger and Udell (1992) for the U.S., Sorensen and Werner (2006) and Gambacorta (2008) for the Euro area, and the Bank of Japan's Financial System Reports for the Japanese economy. ${ }^{6}$ Their explanations rely on credit rationing in recession.

\footnotetext{
${ }^{6}$ For the US, using micro level data, Slovin and Sushka (1983) and Berger and Udell (1992) show that it takes two or more quarters for the private banks to adjust loan interest rates.

For the Euro area, Sorensen and Werner (2006) estimate the incompleteness in the pass-through
} 
There are, however, other aspects relating to stickiness in loan rates. For example, the Bank of Japan's Financial System Reports show that the duration of fixed loan contracts tends to be very long. Also, Graham and Wright (2007) report that a significant proportion of the interest rate payments in some European countries are at a fixed rate. Furthermore, they note that "The associated debt contracts are almost always written in nominal terms, have quite significant associated transactions costs and as a consequence are renegotiated relatively infrequently." 7

Nominal contracts together with infrequent renegotiation are commonly observed exercises in many countries. Thus, the stickiness of loan rates together with imperfect competition in the banking sector are potentially important mechanisms in accounting for the data. In particular, such mechanisms can reproduce one of the important characteristics of monetary policy, interest rate smoothing. Woodford (2003) explains this through the history dependent policy under commitment. Graham and Wright (2007), Kobayashi (2008), and Teranishi (2008) demonstrate that rigidities in loan rate dynamics can also necessitate interest rate smoothing as the optimal policy reaction to shocks. ${ }^{8}$ Fujiwara and Teranishi (2011) also emphasize that the sticky loan mechanism can produce hump-shaped responses to many structural shocks including in response to monetary policy shock. As such empirical studies on monetary policy transmission mechanism using

from the policy interest rate to loan interest rates by the error correction model using macro data. They further show that the degree of the incomplete pass-through significantly differs among countries. Gambacorta (2008) conducts similar analysis for Germany and shows the existence of sticky adjustment in loan interest rates.

For Japan, according to Bank of Japan's Financial System Reports published in March 2007 and 2008, the major city banks need five quarters and the local banks need seven quarters to adjust loan interest rates.

${ }^{7}$ Several studies provide empirical evidence behind these infrequent negotiations, for example, Hannan and Berger (1991) for menu costs, Berger and Udell (1992) for implicit contracts and Calem, Gordy, and Mester (2006) for switching costs.

${ }^{8}$ Contrary to Kobayashi (2008), and Teranishi (2008), stickiness in interest rates is imposed on consumers in Graham and Wright (2007). Thus, the loan interest rate in the IS curve is sticky in Graham and Wright (2007), while in our model, that in the Phillips curve is sticky. 
the Vector Autoregressive models as represented by Christiano, Eichenbaum, and Evans (1999) show, the ability to produce hump-shaped responses is considered to be important for the dynamic stochastic general equilibrium model. As a result, many studies using the dynamic stochastic general equilibrium incorporate habit formation in consumption or investment growth adjustment costs as examined in Christiano, Eichenbaum, and Evans (2005). Sticky loan rates can have hump-shaped properties without relying on these mechanisms. Gerali, Neri, Sessa, and Signoretti (2010) provide empirical evidence of the stickiness in loan contracts in this vein. They estimate the prototypical new Keynesian model, a la Smets and Wouters (2003, 2007) and Christiano, Eichenbaum, and Evans (2005), and extend to replicate the aforementioned features with a monopolistic banking sector and loan rate stickiness.

We then use such a NOEM model with financial frictions in order to analyze the optimal monetary policy under both cooperation and noncooperation. In order to understand how such a simple financial friction as explained above may alter gains from cooperation, we employ a linear quadratic approach for dynamic optimization. For this purpose, the second orderly approximated welfare metric following Benigno and Woodford (2005) and Benigno and Benigno (2006) are also derived.

Welfare analysis shows that there are long-run gains in cooperation. Steady state welfare becomes higher under cooperation. Under noncooperation, each central bank has long-term incentives to raise loan interest rates. This is because high interest rates reduce the labor supply via the cost channel. This result is similar to the one obtained in Cooley and Quadrini (2003). On the other hand, however, dynamically, financial frictions per se do not call for policy cooperation to improve global welfare. Over the business cycle, there is no gain from cooperation except when the global economy is subject to a markup shock. Gains from cooperation in attaining higher global welfare in the presence of the markup shock, however, simply repeats the finding in Benigno and Benigno (2006) with sticky prices. The necessity of cooperation here does not stem from financial market imperfections, but simply from monopolistic competition in the goods 
market. ${ }^{9}$ In addition, inward-looking financial stability, namely eliminating inefficient fluctuations of the loan premium in one's country, is the optimal monetary policy in an open economy irrespective of the existence of the policy coordination. There, each central bank should aim to stabilize fluctuations in the loan premium to firms in its own country. Thus, over the business cycles, the prescription, keep one's house in order, obtained by such previous studies as Clarida, Gali, and Gertler (2002), Benigno and Benigno (2003, 2006) and Woodford (2007), remains valid even with the presence of financial frictions. These results hold when the model is further extended to incorporate international lending and borrowing.

The rest of the paper is structured as follows. Previous studies with similar banking sectors to ours in a dynamic general equilibrium framework are summarized in Section 2. Section 3 derives the model used in this paper and displays its dynamic properties. Section 4 solves the equilibrium under the Ramsey optimal monetary policy in both cooperative and noncooperative regimes. Section 5 derives the quadratic loss functions around the Ramsey optimal steady states obtained in Section 4. These are the welfare measures that central banks aim to minimize. We also investigate the nature of the optimal monetary policy in an open economy with financial frictions. In particular, whether there exists gains from cooperation and whether inward-looking policy can replicate the equilibrium under cooperation are intensively discussed. Finally, Section 6 summarizes the findings of this paper and introduces possible future extensions of this paper.

\section{Related Literature}

Several previous studies incorporate a similar banking sector in a dynamic general equilibrium framework. From the perspective of normative analysis, Kobayashi (2008) and Teranishi (2008) conduct welfare analysis using a model with both sticky prices and

\footnotetext{
${ }^{9}$ The markup shock produces real imperfections in the terminology by Blanchard and Galí (2007). Policy which aims for flexible price equilibrium is no longer optimal when any stickiness either on prices, wages or loan rates exists.
} 
sticky loan rates and report the optimality in policy interest rate smoothing. ${ }^{10}$ On the other hand, from the standpoint of positive analysis, Gerali, Neri, Sessa, and Signoretti (2010), Mandelman (2010, 2011) and Fujiwara and Teranishi (2011) develop models with an imperfectly competitive financial sector. They all conclude that an imperfectly competitive banking sector contributes to a better fit of the model to the data. Gerali, Neri, Sessa, and Signoretti (2010) show that shocks stemming from the banking sector explain the major part of the contraction in the recent financial crisis. Mandelman (2010, 2011) finds that the incorporation of a monopolistic banking sector increases the volatility of real variables and amplifies the business cycle. Fujiwara and Teranishi (2011) explain the persistence of the real exchange rate by incorporating an imperfectly competitive financial sector. On the consequences of monetary cooperation together with financial market imperfections, Cooley and Quadrini (2003) hint that the decline in interest rates after the advent of Euro can be explained by monetary cooperation in a two-country model with the cost channel. No study, however, has investigated whether financial market imperfections call for policy cooperation not only in the long-run but also over business cycles.

For a positive analysis of financial market imperfections, many studies employ the financial accelerator mechanism of Bernanke, Gertler, and Gilchrist (1999) in the dynamic stochastic general equilibrium framework. In the financial accelerator mechanism, the net worth as the state variable causes the deviations of loan rates from the policy interest rate. In our model, instead of the net worth dynamics, the wedge between the loan rate and the policy rate arises due to imperfect competition in firms and thus banks. Accordingly, the dynamics of loan rates are created by staggered loan contracts. The end consequences are, however, similar irrespective of the two ways of modeling financial frictions. A shock related to financial market imperfections eventually results in an increase in the costs of goods production. ${ }^{11}$ The benefit of our approach is that the nature

\footnotetext{
${ }^{10}$ Graham and Wright (2007) do not conduct welfare analysis but show an interesting result on monetary policy. Low interest rates are maintained even after inflationary shocks hit the economy under sticky debt contracts.

${ }^{11}$ There are models where financial market imperfections affect the aggregate TFP. See, for example,
} 
of optimal monetary policy can be understood analytically and therefore intuitively.

\section{Model}

This section describes a two country model with financial frictions. There are four agents in two symmetric countries: consumers; firms; private banks; central banks. We first display the problems solved by each agent and then summarize equilibrium conditions. The main model does not allow banks to lend and borrow internationally. However, financial shocks spill over internationally, through exports and imports. Thus, financial frictions in one country can alter the dynamics of endogenous variables in the other country. The extension of the main model to international lending and borrowing will be discussed in Section 5 .

\subsection{Consumers}

A representative consumer in the home country $H$ maximizes the following welfare $W_{t}$ :

$$
W_{t} \equiv \mathbb{E}_{t} \sum_{T=t}^{\infty} \beta^{T-t}\left\{u\left(C_{T}\right)-\int_{0}^{1} v\left[l_{T}(h)\right] \mathrm{d} h\right\},
$$

where $\mathbb{E}_{t}$ is the expectations operator conditional on the state of nature at date $t$ and $\beta$ is the subjective discount factor. The functions $u$ and $v$ are increasing in the consumption index $C_{t}$ and the labor supply $l_{t}$, respectively. $l_{t}(h)$ denotes the labor supplied to intermediate-goods producing firm $h$.

The budget constraint is given by

$$
\begin{aligned}
P_{t} C_{t}+\mathbb{E}_{t}\left[X_{t, t+1} B_{t+1}\right]+D_{t} \leq & B_{t}+\left(1+i_{t-1}\right) D_{t-1}+\int_{0}^{1} w_{t}(h) l_{t}(h) \mathrm{d} h \\
& +\Pi_{t}^{B}+\Pi_{t}^{F}-T_{t},
\end{aligned}
$$

where $P_{t}$ is the aggregate consumer price index, $B_{t}$ is the Arrow security, $D_{t}$ is the deposit to the private banks, $i_{t}$ is the nominal interest rate set by the central bank from $t-1$ to $t, w_{t}$ is the nominal wage, $\Pi_{t}^{B}=\int_{0}^{1} \Pi_{t}^{B}(h) \mathrm{d} h$ is the nominal dividend from the 
ownership of the private banks in the home country, $\Pi_{t}^{F}=\int_{0}^{1} \Pi_{t}^{F}(h) \mathrm{d} h$ is the nominal dividend from the ownership of intermediate-goods producing firms in the home country, $X_{t, t+1}$ is the stochastic discount factor, and $T_{t}$ is the lump sum tax. ${ }^{12}$

Because a complete financial market between the two countries is assumed, consumers in each country can internationally trade the state contingent securities to insure against country-specific shocks. Consequently, consumers in both countries encounter a unique discount factor. Assuming the complete international financial market in the presence of financial market imperfections may seem unreasonable. These are, however, thought to be important ingredients in explaining economic developments during the recent global financial crisis, in particular, the significant synchronization of the business cycles across different countries. Perri and Quadrini (2011) explain this unprecedented degree of synchronization using a model with credit shocks (financial market imperfections) under the complete international financial market.

\section{$3.2 \quad$ Firms}

\subsubsection{Intermediate-goods producer}

Intermediate-goods producer $h$ produces a differentiated intermediate good $y_{t}$ using the differentiated labor:

$$
y_{t}(h)+y_{t}^{*}(h)=f\left[l_{t}(h)\right],
$$

and needs to borrow loans $q_{t}$ to finance labor compensations:

$$
q_{t}(h)=R_{t}(h) w_{t}(h) l_{t}(h)
$$

where is $R_{t}$ gross loan rates. Intermediate-goods producer $h$ sets the prices in both domestic and foreign markets under the law of one price: ${ }^{13}$

$$
p_{t}(h)=S_{t} p_{t}^{*}(h)
$$

\footnotetext{
${ }^{12}$ The results obtained in this paper will not change even if a deposit to foreign banks or ownership of foreign firms and banks is allowed.

${ }^{13}$ There is no need to assume either producer currency pricing or local currency pricing as there is no price stickiness.
} 
to maximize the profit $\Pi_{t}^{F}$ :

$$
\Pi_{t}^{F}(h)=(1+\tau)\left[p_{t}(h) y_{t}(h)+S_{t} p_{t}^{*}(h) y_{t}^{*}(h)\right]-R_{t}(h) w_{t}(h) l_{t}(h),
$$

where $p_{t}$ and $p_{t}^{*}$ denote prices to home and foreign markets, respectively. ${ }^{14} S_{t}$ is nominal exchange rates. $\tau$ is the sales subsidy, which can be used to eliminate the monopolistic rents in the steady state. The asterisk $*$ denotes foreign variables.

Under the current settings, domestic (foreign) firms borrow only from domestic (foreign) banks. This assumption will be relaxed later in Section 5 to check whether international lending and borrowing alter our main results.

\subsubsection{Final-goods producer}

A final consumption goods producer minimizes the total cost:

$$
P_{H, t} Y_{H, t}+P_{F, t} Y_{F, t}
$$

subject to the following production technology:

$$
Y_{t} \equiv\left(\frac{Y_{H, t}}{\psi}\right)^{\psi}\left(\frac{Y_{F, t}}{1-\psi}\right)^{1-\psi}
$$

where $\psi(0 \leq \psi \leq 1)$ denotes the home bias. $\psi$ is set to 0.5 since symmetry between two countries is assumed. Goods produced in the domestic country $Y_{H, t}$ and those produced in the foreign country $Y_{F, t}$ are defined, respectively, as

$$
Y_{H, t} \equiv\left[\int_{0}^{1} y_{t}(h)^{\frac{\sigma-1}{\sigma}} \mathrm{d} h\right]^{\frac{\sigma}{\sigma-1}},
$$

and

$$
Y_{F, t} \equiv\left[\int_{0}^{1} y_{t}\left(h^{*}\right)^{\frac{\sigma-1}{\sigma}} \mathrm{d} h^{*}\right]^{\frac{\sigma}{\sigma-1}},
$$

where $\sigma$ denotes the elasticity of substitution between differentiated intermediate goods.

\footnotetext{
${ }^{14}$ In this paper, sticky prices are not assumed to solely concentrate on the role of the financial frictions on policy cooperation. There is a trade-off between price stability and financial stability with sticky prices. For details of this trade-off, see Kobayashi (2008) and Teranishi (2008).
} 


\subsection{Private Banks}

There is a continuum of private banks in each country located over [0,1]. Each private bank collects deposits from consumers in its country given saving interest rates. Each bank $h$ is in a long-term relationship with each intermediate-goods producing firm $h$. This follows a segmented banking system supposed in such previous studies as Kobayashi (2008), Andrés and Arce (2009) and Mandelman (2010, 2011). As a result, it sets differentiated nominal loan interest rates according to their individual loan demand curves. Differentiated nominal loan interest rate applies to differentiated intermediate-goods producers. Thus, within this segmented environment, private banks maintain monopoly power over the loan interest rate determination. ${ }^{15}$

In addition, each bank resets its loan interest rates with probability $1-\phi$ following the Calvo (1983) - Yun (1996) framework as examined in Teranishi (2008) and Fujiwara and Teranishi (2011). Due to staggered loan contracts between firms and private banks, private banks end up fixing nominal loan interest rates for a certain period. Staggered loan contracts also generate dispersions in loan interest rates, which result in welfare costs.

The private bank $h$ sets the loan interest rate to maximize the present discounted value of profit:

$$
\mathbb{E}_{t} \sum_{T=t}^{\infty} \phi^{T-t} X_{t, T} \Pi_{T}^{B}(h),
$$

where

$$
\Pi_{t}^{B}(h)=q_{t}(h)\left[(1+\tau) R_{t}(h)-\left(1+i_{t}\right) \exp \left(u_{t}\right)\right]
$$

$u_{t}$ denotes the loan premium shock. $\tau$ is the subsidy to private banks, which can again be used to eliminate the monopolistic rents in the steady state.

\footnotetext{
${ }^{15}$ Almost identical results are obtained with the assumption of the monopolistically competitive banking sector as examined in Teranishi (2008), Gerali, Neri, Sessa, and Signoretti (2010) and Fujiwara and Teranishi (2011).
} 


\subsection{Preference and Parameter}

$u(\cdot)$ and $v(\cdot)$ are iso-elastic functions:

$$
u(c)=\frac{c^{1-v}}{1-v}
$$

and

$$
v(l)=l
$$

Firms are equipped with a linear production technology:

$$
f(l)=\exp \left(z_{t}\right) l
$$

where $z_{t}$ denotes the technology shock. Appendix A displays the detailed derivation for the system of equations.

\subsection{Market Clearing Conditions}

Equation (3) together with the foreign counterpart depict the market clearing conditions for intermediate goods. The market clearing conditions for final goods are simply

$$
C_{t}=Y_{t}
$$

and

$$
C_{t}^{*}=Y_{t}^{*}
$$

\subsection{System of Equations}

11 equilibrium conditions below, together with the optimal monetary policy defined in the next section determine the optimal paths for $R, F, K, Y, R^{*}, F^{*}, K^{*}, l, l^{*}, \Delta, \Delta^{*}$, $i$ and $i^{*}$ :

$$
\begin{gathered}
{\left[\frac{1-\phi\left(\frac{R_{t-1}}{R_{t}}\right)^{1-\sigma}}{1-\phi}\right]^{\frac{1}{1-\sigma}} F_{t}=K_{t},} \\
F_{t}=1+\beta \phi \mathbb{E}_{t} \frac{Y_{t+1}^{1-v}}{Y_{t}^{1-v}}\left(\frac{R_{t}}{R_{t+1}}\right)^{1-\sigma} F_{t+1},
\end{gathered}
$$




$$
\begin{aligned}
& K_{t}=\frac{\sigma \exp \left(\mu_{t}\right)}{(1+\tau)(\sigma-1)} \frac{\left(1+i_{t}\right) \exp \left(u_{t}\right)}{R_{t}}+\mathbb{E}_{t} \beta \phi \frac{Y_{t+1}^{1-v}}{Y_{t}^{1-v}}\left(\frac{R_{t}}{R_{t+1}}\right)^{-\sigma} K_{t+1}, \\
& {\left[\frac{1-\phi\left(\frac{R_{t-1}^{*}}{R_{t}^{*}}\right)^{1-\sigma}}{1-\phi}\right]^{\frac{1}{1-\sigma}} F_{t}^{*}=K_{t}^{*}} \\
& F_{t}^{*}=1+\beta \phi \mathbb{E}_{t} \frac{Y_{t+1}^{1-v}}{Y_{t}^{1-v}}\left(\frac{R_{t}^{*}}{R_{t+1}^{*}}\right)^{1-\sigma} F_{t+1}^{*}, \\
& K_{t}^{*}=\frac{\sigma}{(1+\tau)(\sigma-1)} \frac{\left(1+i_{t}^{*}\right)}{R_{t}^{*}}+\mathbb{E}_{t} \beta \phi \frac{Y_{t+1}^{1-v}}{Y_{t}^{1-v}}\left(\frac{R_{t}^{*}}{R_{t+1}^{*}}\right)^{-\sigma} K_{t+1}^{*}, \\
& \frac{(1+\tau)(\sigma-1)}{\exp \left(\mu_{t}\right) \sigma} \frac{Y_{t}^{1-v} \Delta_{t}}{R_{t}}=l_{t}, \\
& \Delta_{t}=(1-\phi)\left[\frac{1-\phi\left(\frac{R_{t-1}}{R_{t}}\right)^{1-\sigma}}{1-\phi}\right]^{\frac{\sigma}{\sigma-1}}+\phi\left(\frac{R_{t-1}}{R_{t}}\right)^{-\sigma} \Delta_{t-1} \text {, } \\
& \frac{(1+\tau)(\sigma-1)}{\sigma} \frac{Y_{t}^{1-v} \Delta_{t}^{*}}{R_{t}^{*}}=l_{t}^{*}, \\
& \Delta_{t}^{*}=(1-\phi)\left[\frac{1-\phi\left(\frac{R_{t-1}^{*}}{R_{t}^{*}}\right)^{1-\sigma}}{1-\phi}\right]^{\frac{\sigma}{\sigma-1}}+\phi\left(\frac{R_{t-1}^{*}}{R_{t}^{*}}\right)^{-\sigma} \Delta_{t-1}^{*} \text {, }
\end{aligned}
$$

and

$$
1=\left[\frac{\sigma}{(1+\tau)(\sigma-1)} Y_{t}^{v}\right]^{2} \exp \left(\mu_{t}\right)\left[\frac{R_{t}}{\exp \left(z_{t}\right)}\right] R_{t}^{*},
$$

where a negative markup shock $\mu_{t}$ is added. ${ }^{16}$ Benigno and Benigno (2006) show that there are gains in monetary cooperation with the markup shock in a standard two-country sticky price model even with the producer currency pricing.

Similarly to Yun (2005), equations (14) to (16) and equations (17) to (19) represent the recursive representations for domestic and foreign loan Phillips curves respectively. The first-order log-linear approximation on these equations around the Ramsey optimal steady states $\left(\hat{x}_{t} \equiv \log \left(X_{t} / X\right) \approx\left(X_{t}-X\right) / X\right.$, where $X$ is the Ramsey optimal steady state value) leads to the domestic loan rate Phillips curve:

$$
\left(\hat{R}_{t}-\hat{R}_{t-1}\right)=\beta \mathbb{E}_{t}\left(\hat{R}_{t+1}-\hat{R}_{t}\right)+\frac{(1-\phi)(1-\beta \phi)}{\phi}\left(i_{t}+u_{t}+\mu_{t}-\hat{R}_{t}\right),
$$

\footnotetext{
${ }^{16}$ This can be considered as a shock to the subsidy $\tau$. All shocks including this markup shock are applied only to the domestic country.
} 
and the foreign loan rate Phillips curve:

$$
\left(\hat{R}_{t}^{*}-\hat{R}_{t-1}^{*}\right)=\beta \mathbb{E}_{t}\left(\hat{R}_{t+1}^{*}-\hat{R}_{t}^{*}\right)+\frac{(1-\phi)(1-\beta \phi)}{\phi}\left(i_{t}^{*}-\hat{R}_{t}^{*}\right) .
$$

Equations (25) and (26) are quite analogous to the new Keynesian Phillips curve. Instead of inflation rates, that are defined as $\hat{\pi}_{t}=\hat{P}_{t}-\hat{P}_{t-1}$, here inflation rates for gross loan rates $\left(\hat{R}_{t}-\hat{R}_{t-1}\right)$ are determined by loan inflation expectation $\mathbb{E}_{t}\left(\hat{R}_{t+1}-\hat{R}_{t}\right)$ and (nominal) marginal costs of loan creation $\left(i_{t}+u_{t}+\mu_{t}-\hat{R}_{t}\right)$. Loan interest rates affect marginal costs with the presence of the cost channel as equations (4), (25) and (26) illustrate. Therefore, contrary to the standard new Keynesian model, inflation rates (of loan rates) as well as the price level (of loan rates) are pinned down by the model. Consequently, backward-looking components in equations (25) and (26), namely $\hat{R}_{t-1}$ and $\hat{R}_{t-1}^{*}$, become the endogenous state variables in this model. Note also that steady states do not matter for linearized aggregate supply conditions.

Equations (21) and (23) show the dynamics of relative loan rate dispersions, that are defined as

$$
\Delta_{t} \equiv \int_{0}^{1}\left[\frac{R_{t}(h)}{R_{t}}\right]^{-\sigma} \mathrm{d} h,
$$

and

$$
\Delta_{t}^{*} \equiv \int_{0}^{1}\left[\frac{R_{t}^{*}\left(h^{*}\right)}{R_{t}^{*}}\right]^{-\sigma} \mathrm{d} h^{*} .
$$

Since each bank only resets its loan interest rates with probability $1-\phi$, equations (21) and (23) are derived from the definition of the average loan rates:

$$
R_{t} \equiv\left[\int_{0}^{1} R_{t}(h)^{1-\sigma} \mathrm{d} h\right]^{\frac{1}{1-\sigma}}
$$

and

$$
R_{t}^{*} \equiv\left[\int_{0}^{1} R_{t}^{*}\left(h^{*}\right)^{1-\sigma} \mathrm{d} h^{*}\right]^{\frac{1}{1-\sigma}} .
$$

As is well-known in the literatures with the new Keynesian model, relative price dispersion matters only under higher order than linear approximation. This is because with linear approximation,

$$
\hat{\Delta}_{t}=\hat{\Delta}_{t}^{*}=0
$$


Equations (20) and (22) are derived from the market clearing conditions for intermediate goods in equation (3) and its foreign counterpart. As is the case with the standard new Keynesian model with sticky prices, relative price dispersion terms in equations (27) and (28) act as if they were negative technology shocks. As a result, price stability, or loan rate stability in this paper, becomes the optimal monetary policy.

Equation (24) is the market clearing condition for the final goods in equations (12) and (13) under the complete international financial market. This can be also expressed as log-deviation from the Ramsey optimal steady states as

$$
0=\mu_{t}+2 v \hat{Y}_{t}+\hat{R}_{t}-z_{t}+\hat{R}_{t}^{*}
$$

Consumption Euler equation for the domestic country:

$$
Y_{t}^{-v}=\beta\left(1+i_{t}\right) \mathbb{E}_{t}\left(\frac{Y_{t+1}^{-v}}{\pi_{t+1}}\right),
$$

and that for the foreign country:

$$
\left(Y_{t}^{*}\right)^{-v}=\beta\left(1+i_{t}^{*}\right) \mathbb{E}_{t}\left[\frac{\left(Y_{t+1}^{*}\right)^{-v}}{\pi_{t+1}^{*}}\right],
$$

can be included in addition to equilibrium conditions (14) to (24). These will determine CPI inflation expectations in both countries. In such a model, however, indeterminacy in inflation rates arises. In order to avoid this indeterminacy, sticky price mechanism must be incorporated in intermediate goods firms' profit maximization problem in equations (6). This will, however, complicate the analysis, especially in the open economy. Thus, nominal price rigidities are abstracted from the model and CPI inflation rates are left to be indeterminate in this model. ${ }^{17}$

In this economy, there are three distortions; suboptimally low production due to monopolistic rents; working capital loans; staggered loan contracts. The first distortion

\footnotetext{
${ }^{17}$ Analytical solutions cannot be obtained with nominal price rigidity in addition to the loan rate stickiness. Previous studies on the optimal monetary policy in the presence of the cost channel, such as Ravenna and Walsh (2006) and Teranishi (2008) assume that the difference between the Ramsey optimal steady state and the steady state under flexible price equilibrium is very small and negligible. This is a strong assumption, as approximation must be conducted around the Ramsey optimal steady state. For a detailed discussion of this issue, see Fujiwara and Nakazono (2013).
} 
Figure 1: Responses to Monetary Policy Shock
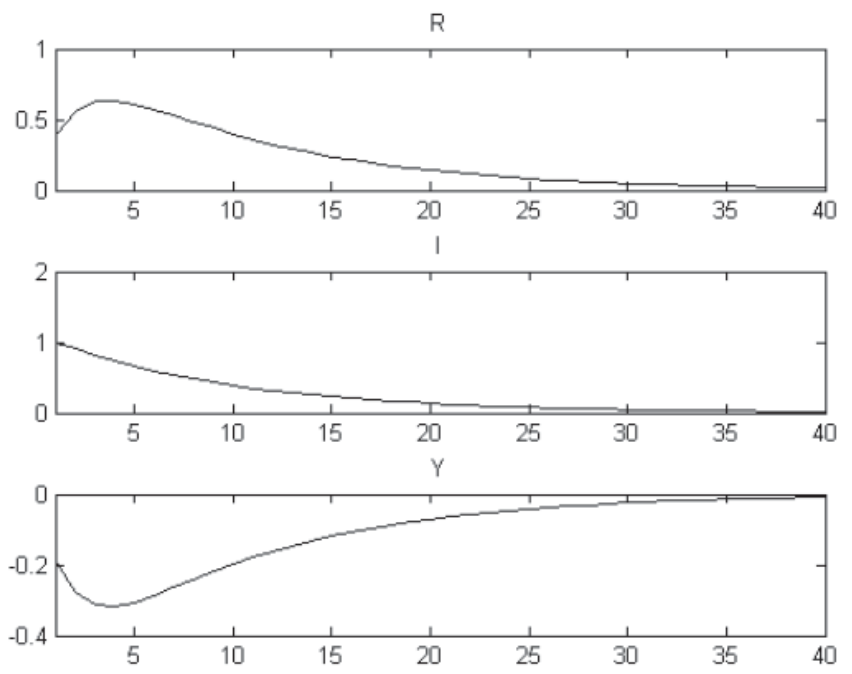

is eliminted by an appropriate subsidy. The optimal monetary policy aims to minimize the welfare costs stemming from the second and third distortions.

\subsection{Dynamic Properties}

Here, we display the dynamic property of this model to the monetary policy shock. Even though the model is quite simple and stylized, it can capture important properties in the monetary transmission mechanism, namely, the delayed responses in loan rates and hump-shaped responses of output and consumption. In the simplest form, the linearized equilibrium conditions in equations (25), (26) and (30) given policy interest rates can determine the equilibrium paths for domestic loan rates $R_{t}$. foreign loan rates $R_{t}^{*}$ and final goods production (consumption in both domestic and foreign countries) $Y_{t}{ }^{18}$ Figure 1 illustrates the responses of these variables to the monetary policy shock. The parameters are calibrated as in Table 1. $\beta$ and $\sigma$ are taken from Steinsson (2008), and $\phi$ is the average value of loan rate stickiness across the countries estimated in Fujiwara and

\footnotetext{
${ }^{18}$ The existence of lagged loan rates in equations (25) and (26) and the absence of the determination of inflation rates gives the model quite different implications regarding indeterminacy stemming from monetary policy rules.
} 
Table 1: Parameter Values

\begin{tabular}{lll}
\hline \hline Parameters & Values & Explanation \\
\hline$\beta$ & 0.99 & Subjective discount factor \\
$v$ & 2 & Coefficient of relative risk aversionect to real interest rate \\
$\phi$ & 0.57 & Probability of loan interest rate change \\
$\sigma$ & 7.66 & Substitutability of differentiated consumption goods \\
\hline
\end{tabular}

Teranishi (2011). The monetary policy shock follows the AR(1) process with a parameter of 0.9 .

Due to the existence of staggered loan contracts, the initial response of domestic loan rates becomes significantly smaller compared to changes in domestic policy interest rates. Thus, delayed responses on loan rates reported by such previous studies as Slovin and Sushka (1983), Berger and Udell (1992), Sorensen and Werner (2006), Graham and Wright (2007), Gambacorta (2008) and Gerali, Neri, Sessa, and Signoretti (2010) materialize in this model. In addition, the responses of $Y_{t}$, that is the final output and therefore consumption in both domestic and foreign countries, demonstrate humpshaped dynamics, often considered an important property for the dynamic stochastic general equilibrium model to replicate. Hump-shaped responses stem from lagged loan rates in equations (25) and (26) as endogenous state variables. Unlike the standard new Keynesian model with sticky prices, the level of nominal variables, that are price levels in the new Keynesian model and the levels of loan rates in our model, constrain real variables through the working capital loan.

The foreign loan rate Phillips curve in equation (26) contains only foreign loan and policy interest rates. A shock also only impacts upon domestic policy interest rates. Thus, foreign loan rates remain at a steady state level in this simulation. Through an increase in domestic loan rates, however, consumption in the foreign county also decreases due to the cost channel of monetary policy under the complete international financial market. We will consider optimal reactions by both domestic and foreign central banks 
in the following sections.

\section{Ramsey Policy}

In this section, the Ramsey optimal monetary policy under both cooperation and noncooperation will be discussed. We aim to intuitively understand the optimal monetary policy in an open economy with financial frictions. We will therefore scrutinize the nature of optimal monetary policy in a linear quadratic framework introduced in the next section. There are two main aims of deriving the allocations under the Ramsey optimal monetary policy in this section: to compute the optimal Ramsey optimal steady state around which the model should be approximated; to understand whether there are gains from cooperation in the long-run.

\subsection{Cooperation}

Under cooperation, two central banks aim to maximize global welfare together:

$$
\begin{aligned}
W_{t}+W_{t}^{*} & \equiv \mathbb{E}_{t} \sum_{T=t}^{\infty} \beta^{T-t}\left[\frac{C_{T}^{1-v}}{1-v}+\frac{\left(C_{T}^{*}\right)^{1-v}}{1-v}-\int_{0}^{1} l_{T}(h) \mathrm{d} h-\int_{0}^{1} l_{T}\left(h^{*}\right) \mathrm{d} h^{*}\right] \\
& =\mathbb{E}_{t} \sum_{T=t}^{\infty} \beta^{T-t}\left(\frac{2 Y_{T}^{1-v}}{1-v}-l_{T}-l_{T}^{*}\right)
\end{aligned}
$$

where equations (12) and (13) are substituted, subject to equilibrium conditions in equations (14) to (24). Appendix B provides all equilibrium conditions involving Lagrange multipliers on the constraints of this problem. These determine the allocations under the optimal monetary policy in cooperation.

\subsection{Noncooperation}

Under noncooperation, the game between two central banks must be well-defined. In particular, we must clarify the action of the opponent which is taken as given. In this paper, we solve the open-loop Nash equilibrium, where the domestic (foreign) central bank maximizes welfare of domestic (foreign) country given the policy interest rate in 
the foreign (domestic) country. Clarida, Gali, and Gertler (2002) assume output in the other country to be given, while producer price inflation rates in the other country are considered to be given in Benigno and Benigno (2003, 2006). In the model considered in this paper, there is neither country specific output nor inflation as can be seen in equations (14) to (24). Consequently, the natural variable to be given as exogenous to each central bank is the policy interest rate in the counterpart country.

Given the policy interest rate in the foreign country $i_{t}^{*}$, the domestic central bank maximizes welfare in the domestic country:

$$
\begin{aligned}
W_{t} & \equiv \mathbb{E}_{t} \sum_{T=t}^{\infty} \beta^{T-t}\left[\frac{C_{T}^{1-v}}{1-v}-\int_{0}^{1} l_{T}(h) \mathrm{d} h\right] \\
& =\mathbb{E}_{t} \sum_{T=t}^{\infty} \beta^{T-t}\left(\frac{Y_{T}^{1-v}}{1-v}-l_{T}\right)
\end{aligned}
$$

subject to equilibrium conditions in equations (14) to (24).

Similarly, the foreign central bank takes the policy interest in the domestic country $i_{t}$ as given and maximizes welfare in the foreign country:

$$
W_{t}^{*} \equiv \mathbb{E}_{t} \sum_{T=t}^{\infty} \beta^{T-t}\left(\frac{Y_{T}^{1-v}}{1-v}-l_{T}^{*}\right),
$$

subject to equilibrium conditions in equations (14) to (24).

Appendix B provides all equilibrium conditions involving Lagrange multipliers on the constraints in this problem under noncooperation. These determine the allocations under the optimal monetary policy in noncooperation.

\subsection{Ramsey Optimal Steady State}

The Ramsey optimal steady states are computed from equilibrium conditions by eliminating time subscripts. The aim of computing the Ramsey optimal steady states is twofold. First, we will derive the optimal monetary policy in the linear quadratic framework following Benigno and Woodford (2005) and Benigno and Benigno (2006). This is because intuition for the optimal monetary policy can hardly be understood from the non-linear equilibrium conditions shown in Appendix B. Linear quadratic approximation 
must be conducted around the Ramsey optimal steady states. Second, the differences between cooperative and noncooperative regimes imply the existence of gains from policy cooperation in the long-run, or under no loan rate stickiness. ${ }^{19}$

Appendix B shows the Ramsey optimal steady state for all variables under both cooperation (with subscript $C$ ) and noncooperation (with subscript $N$ ) . Here, only the Ramsey optimal steady states of endogenous variables except for auxiliary variables and the Lagrange multipliers are displayed. The Ramsey optimal steady states of policy interest rates, output, labor supply and loan interest rates under cooperation are as follows:

$$
\begin{gathered}
1+i_{C}=1+i_{C}^{*}=\left[\frac{(1+\tau)(\sigma-1)}{\sigma}\right]^{2}, \\
Y_{C}=l_{C}=l_{C}^{*}=1,
\end{gathered}
$$

and

$$
R_{C}=R_{C}^{*}=\frac{(1+\tau)(\sigma-1)}{\sigma}
$$

On the other hand, those under noncooperation are

$$
\begin{gathered}
1+i_{N}=1+i_{N}^{*}=(1+v)\left[\frac{(1+\tau)(\sigma-1)}{\sigma}\right]^{2}, \\
Y_{N}=l_{N}=l_{N}^{*}=\left(\frac{1}{1+v}\right)^{\frac{1}{v}}
\end{gathered}
$$

and

$$
R_{N}=R_{N}^{*}=(1+v) \frac{(1+\tau)(\sigma-1)}{\sigma} .
$$

Since the coefficient of the relative risk aversion, or, the inverse of the intertemporal elasticity of substitution, is positive $(v>0)$, both policy and loan interest rates are higher under the noncooperative regime $\left(i_{N}>i_{C}, R_{N}>R_{C}\right)$. Regarding output and labor supply, since

$$
\frac{d\left(\frac{1}{1+v}\right)^{\frac{1}{v}}}{d v}=\frac{d \exp \left[\frac{1}{v} \log \left(\frac{1}{1+v}\right)\right]}{d v}=\exp \left[\frac{1}{v} \log \left(\frac{1}{1+v}\right)\right]\left[\frac{1+v}{v}+\frac{\log (1+v)}{v^{2}}\right]>0
$$

\footnotetext{
${ }^{19}$ This is because only the loan stickiness creates the dynamics in this model.
} 
whether or not it becomes larger under cooperation depends on the size of $v$. Appendix $\mathrm{C}$ proves that steady state welfare is indeed higher under cooperation. ${ }^{20}$

\subsection{Cooperation vs Noncooperation in the Long-Run}

The Ramsey optimal steady states under cooperation are different from those under noncooperation. In addition, steady state welfare is naturally higher under cooperation. Together these imply that there is welfare gain from cooperation in the long-run. Here, we aim to understand the sources of this long-run welfare gain.

In the absence of shocks and nominal (loan rate) rigidities, equilibrium conditions in equations (14) to (24) collapse to the five equations below:

$$
\begin{gathered}
\frac{(1+\tau)(\sigma-1)}{\sigma} \frac{Y_{f, t}^{1-v}}{1+i_{f, t}}=l_{f, t}, \\
\frac{(1+\tau)(\sigma-1)}{\sigma} \frac{Y_{f, t}^{1-v}}{1+i_{f, t}^{*}}=l_{f, t}^{*}, \\
1=\left[\frac{\sigma}{(1+\tau)(\sigma-1)} Y_{f, t}^{v}\right]^{2}\left(1+i_{f, t}\right)\left(1+i_{f, t}^{*}\right), \\
R_{f, t}=\frac{\sigma}{(1+\tau)(\sigma-1)}\left(1+i_{f, t}\right),
\end{gathered}
$$

and

$$
R_{f, t}^{*}=\frac{\sigma}{(1+\tau)(\sigma-1)}\left(1+i_{f, t}^{*}\right),
$$

where the variables in this economy are denoted with subscript $f$. They can be also obtained by eliminating time subscripts in equilibrium conditions in equations (14) and (24). Thus, optimal policy analysis here can be considered to compute the golden rule allocation in the terminology of King and Wolman (1999).

\footnotetext{
${ }^{20}$ The model involves endogenous state variables, namely $R_{t}$ and $R_{t}^{*}$. Thus, steady state welfare comparison may not be a good measure for evaluating the (policy) regimes. In particular, when the steady states for endogenous state variables are different, the steady states under the Pareto optimal allocation can be lower than those under alternative policy. For a detailed discussion on this point, see Bilbiie, Fujiwara, and Ghironi (2011).
} 
The problem under cooperation is to maximize welfare defined in (31) subject to equations (36) to (38), while the domestic (foreign) central bank under the noncooperative regime aims to maximize welfare defined in (32) ((33)) subject also to equations (36) to (38). The optimal allocations obtained from these problems are identical to the Ramsey optimal steady states, derived in the previous section. The differences in the Ramsey optimal steady states between cooperation and noncooperation can be understood from this simplified optimization problem for the golden rule allocations.

Equations (36) to (38) clarify the reason behind the differences. Equations (36) and (37) demonstrate that each central bank has an incentive to keep the policy interest rates high to reduce the dis-utility stemming from labor supply. Corsetti and Pesenti (2001) call this incentive the deflationary bias. With the working capital loan and the complete financial market, the terms of trade $T o T_{t}$ can be expressed with the ratio of domestic over foreign loan rates: ${ }^{21}$

$$
T_{o} T_{t}=\frac{S_{t} P_{H, t}^{*}}{P_{F, t}}=\frac{R_{t}}{R_{t}^{*}} .
$$

Thus, each central bank aims to keep higher interest rates to improve the terms of trade.

On the other hand, equation (38), which is derived from the market clearing condition for final goods in equations (12) and (13) under the complete international financial market, shows that with globally lowered interest rates, both countries can enjoy more consumption and therefore higher welfare. Under the complete international financial market, it is not the policy interest rate in each individual country, but global interest rates, that is the arithmetic mean of interest rates of two countries, which determines global consumption and therefore consumption in each country. This becomes the source of the externality, which creates incentives for central banks to keep interest rates higher. Central banks under cooperation can internalize this externality. Consequently, interest rates under cooperation are lower than under noncooperation. Thus, there are gains in cooperation with the cost channel in the long-run. ${ }^{22}$

\footnotetext{
${ }^{21}$ For the detailed derivation, see Appendix A, in particular, equations (92) to (95).

${ }^{22}$ Cooley and Quadrini (2003) explain the decline in interest rates after the advent of Euro were caused by monetary cooperation.
} 
If a subsidy is employed to eliminate the steady state distortion from monopolistic competition, equation (34) collapses to

$$
R_{C}=R_{C}^{*}=1
$$

Net interest rates are zero so the welfare costs stemming from the working capital loan becomes zero. This result under cooperation is considered to be a result of the Friedman rule with the cost channel in eliminating nominal distortions. Zero net nominal interest rates together with negative inflation rates become optimal. Thus, the second distortion can be eliminated by the appropriate steady state conditions with negative inflation targeting. Note also that this welfare gain from cooperation in the long-run arises even with the log utility, $v=1$.

\section{Optimal Monetary Policy in LQ Framework}

The previous section clarifies that there are gains in cooperation in the long-run. In this section, we delve into whether gains exist even in the short-run, in particular, in optimal responses to structural shocks.

For this, we need to compare the optimal paths to shocks of all endogenous variables between cooperation and noncooperation using equilibrium conditions in Appendix B. ${ }^{23}$ Yet, there are too many equations, in particular, for auxiliary variables and co-state variables. Instead, in this section, we investigate the nature of the Ramsey optimal policy using the linear quadratic framework proposed by Benigno and Woodford (2005) and Benigno and Benigno (2006). ${ }^{24}$

\footnotetext{
${ }^{23}$ Naturally, the same impulse responses are obtained under both non-linear and linear quadratic Ramsey problems.

${ }^{24}$ Benigno and Benigno (2006) is the application of Benigno and Woodford (2005) to a two country model. De Paoli (2009) derives the linear quadratic loss function in a small open economy using this technique.
} 


\subsection{Loss Function under Cooperation}

We first approximate welfare under cooperation in (31) up to the second order. We use the second order log approximation:

$$
\frac{X_{t}-X}{X} \approx \hat{x}_{t}+\frac{1}{2} \hat{x}_{t}^{2} .
$$

Then, welfare under cooperation in (31) is approximated around the Ramsey optimal steady state as

$$
\begin{aligned}
W_{t}+W_{t}^{*} & \equiv \mathbb{E}_{t} \sum_{T=t}^{\infty} \beta^{T-t}\left(\frac{2 Y_{T}^{1-v}}{1-v}-l_{T}-l_{T}^{*}\right) \\
& \approx \mathbb{E}_{t} \sum_{t=0}^{\infty} \beta^{t}\left[2 \hat{Y}_{t}-\hat{l}_{t}-\hat{l}_{t}^{*}+(1-v) \hat{Y}_{t}^{2}-\frac{1}{2} \hat{l}_{t}^{2}-\frac{1}{2}\left(\hat{l}_{t}^{*}\right)^{2}\right] .
\end{aligned}
$$

Note that terms that are higher order terms than 2nd order and independent from policy will not be shown hereafter.

By taking logs for equations (20) and (22), we have

$$
(1-v) \hat{Y}_{t}-\mu_{t}-\hat{R}_{t}+\hat{\Delta}_{t}=\hat{l}_{t}
$$

and

$$
(1-v) \hat{Y}_{t}-\hat{R}_{t}^{*}+\hat{\Delta}_{t}^{*}=\hat{l}_{t}^{*} .
$$

In addition, second order approximation to equations (21) and (23) leads to

$$
\mathbb{E}_{t} \sum_{t=0}^{\infty} \beta^{t} \Delta_{t} \approx \mathbb{E}_{t} \sum_{t=0}^{\infty} \beta^{t} \frac{\phi \sigma}{2(1-\phi)(1-\beta \phi)}\left(\hat{R}_{t}-\hat{R}_{t-1}\right)^{2},
$$

and

$$
\mathbb{E}_{t} \sum_{t=0}^{\infty} \beta^{t} \Delta_{t}^{*} \approx \mathbb{E}_{t} \sum_{t=0}^{\infty} \beta^{t} \frac{\phi \sigma}{2(1-\phi)(1-\beta \phi)}\left(\hat{R}_{t}^{*}-\hat{R}_{t-1}^{*}\right)^{2} .
$$

By substituting equations (41) to (44) into (40), the quadratic loss function under cooperation is derived:

$$
-\left(W_{t}+W_{t}^{*}\right) \equiv L_{t} \approx \mathbb{E}_{t} \sum_{t=0}^{\infty} \beta^{t}\left\{\begin{array}{c}
\frac{\phi \sigma}{2(1-\phi)(1-\beta \phi)}\left(\hat{R}_{t}-\hat{R}_{t-1}\right)^{2}+\frac{\phi \sigma}{2(1-\phi)(1-\beta \phi)}\left(\hat{R}_{t}^{*}-\hat{R}_{t-1}^{*}\right)^{2} \\
+\frac{1}{2}\left(\hat{R}_{t}+\mu_{t}\right)^{2}+\frac{1}{2}\left(\hat{R}_{t}^{*}\right)^{2} \\
+\frac{1-v}{4 v}\left[\left(\hat{R}_{t}+\mu_{t}\right)+\hat{R}_{t}^{*}\right]^{2}
\end{array}\right\} .
$$


The loss function in equation (45) shows that global welfare is represented by not only the loan inflation rate, namely difference $\left(\hat{R}_{t}-\hat{R}_{t-1}\right)$, but also the level of loan interest rates $\hat{R}_{t}$. The former captures welfare costs stemming from relative loan rate dispersions in equations (27) and (28). The latter representss welfare losses from unsmoothed consumption. The cost channel controls the equilibrium dynamics in consumption and therefore, loan rates remain in the approximated loss function to represent welfare gain from consumption smoothing.

\subsection{Loss Functions under Noncooperation}

Under noncooperation, the loss functions for both domestic and foreign central banks are computed separately. The domestic welfare under noncooperation in (32) is approximated up to the second order as

$$
\begin{aligned}
W_{t} & \equiv \mathbb{E}_{t} \sum_{T=t}^{\infty} \beta^{T-t}\left(\frac{Y_{T}^{1-v}}{1-v}-l_{T}\right) \\
& \approx\left(\frac{1}{1+v}\right)^{\frac{1}{v}} \mathbb{E}_{t} \sum_{t=0}^{\infty} \beta^{t}\left[(1+v) \hat{Y}_{t}-\hat{l}_{t}+\frac{(1+v)(1-v)}{2} \hat{Y}_{t}^{2}-\frac{1}{2} \hat{l}_{t}^{2}\right] .
\end{aligned}
$$

After substituting equations (41) to (43) and ignoring the parameters before the summation, this collapses to

$$
-\mathbb{E}_{t} \sum_{t=0}^{\infty} \beta^{t}\left\{\begin{array}{c}
\hat{R}_{t}^{*}+\frac{\phi \sigma}{2(1-\phi)(1-\beta \phi)}\left(\hat{R}_{t}-\hat{R}_{t-1}\right)^{2} \\
-\frac{(1-v)}{4 v}\left[\left(\hat{R}_{t}^{*}-z_{t}\right)^{2}+\left(\hat{R}_{t}+\mu_{t}\right)^{2}\right]+\frac{1}{2}\left(\hat{R}_{t}+\mu_{t}\right)^{2}
\end{array}\right\} .
$$

Contrary to the loss function under cooperation in (45), the linear term $\hat{R}_{t}^{*}$ still remains. Linear term in welfare metric will result in spurious welfare evaluation in linear quadratic framework. ${ }^{25}$ Here, following Benigno and Woodford (2005) and Benigno and Benigno (2006), we take the second order approximation to equilibrium conditions and obtain the approximated equations where linear terms are expressed only by quadratic terms. By using such second orderly approximated equilibrium conditions, we can substitute out linear terms in the welfare metric with quadratic terms.

\footnotetext{
${ }^{25}$ For details on this, see, for example, Sutherland (2002), Kim and Kim (2003, 2007), Benigno and Woodford (2005, 2012) and Kim, Kim, Schaumburg, and Sims (2008).
} 
Appendix D shows further detail of how to derive the quadratic approximation of the loan rate Phillips curves in equations (14) to (16) or (17) to (19). From the second order approximation of the loan rate Phillips curve in the foreign country in equations (17) to (19), we can derive

$$
\mathbb{E}_{t} \sum_{t=0}^{\infty} \beta^{t}\left(i_{t}^{*}-\hat{R}_{t}^{*}\right) \approx \mathbb{E}_{t} \sum_{t=0}^{\infty} \beta^{t}\left[\begin{array}{c}
-(1-v) \hat{Y}_{t}\left(i_{t}^{*}-\hat{R}_{t}^{*}\right)-\frac{1}{2}\left(i_{t}^{*}-\hat{R}_{t}^{*}\right)^{2} \\
-\frac{\sigma \phi}{2(1-\beta \phi)(1-\phi)}\left(\hat{R}_{t}^{*}-\hat{R}_{t-1}^{*}\right)^{2}
\end{array}\right] .
$$

By substituting this approximated relationship in (48) into the approximated welfare measure in (47), we can derive the quadratic loss function which the domestic central bank aims to minimize:

$$
L_{t}^{D} \approx \mathbb{E}_{t} \sum_{t=0}^{\infty} \beta^{t}\left\{\begin{array}{c}
\frac{\sigma \phi}{2(1-\beta \phi)(1-\phi)} \\
\left(\hat{R}_{t}-\hat{R}_{t-1}\right)^{2}+\frac{\phi \sigma}{2(1-\phi)(1-\beta \phi)}\left(\hat{R}_{t}^{*}-\hat{R}_{t-1}^{*}\right)^{2} \\
+\frac{1}{2}\left(\hat{R}_{t}+\mu_{t}\right)^{2}+\frac{1}{2}\left(\hat{R}_{t}^{*}-i_{t}^{*}\right)^{2} \\
+\frac{1-v}{4 v}\left[\left(\hat{R}_{t}+\mu_{t}\right)+\left(\hat{R}_{t}^{*}-i_{t}^{*}\right)\right]^{2}
\end{array}\right\} .
$$

Similarly, from the second order approximation of the loan rate Phillips curve in the domestic country in equations (14) to (16), we can obtain

$$
\mathbb{E}_{t} \sum_{t=0}^{\infty} \beta^{t}\left(i_{t}-\hat{R}_{t}+u_{t}+\mu_{t}\right) \approx \mathbb{E}_{t} \sum_{t=0}^{\infty} \beta^{t}\left\{\begin{array}{c}
-\left[z_{t}+(1-v) \hat{Y}_{t}\right]\left(i_{t}+\mu_{t}+u_{t}-\hat{R}_{t}\right) \\
-\frac{1}{2}\left(i_{t}+u_{t}+\mu_{t}-\hat{R}_{t}\right)^{2} \\
-\frac{\sigma \phi}{2(1-\beta \phi)(1-\phi)}\left(\hat{R}_{t}-\hat{R}_{t-1}\right)^{2}
\end{array}\right\}
$$

By using this approximated relationship in (50), we can derive the quadratic loss function for the foreign central bank as

$$
L_{t}^{F} \approx \mathbb{E}_{t} \sum_{t=0}^{\infty} \beta^{t}\left\{\begin{array}{c}
\frac{\sigma \phi}{2(1-\beta \phi)(1-\phi)}\left(\hat{R}_{t}-\hat{R}_{t-1}\right)^{2}+\frac{\phi \sigma}{2(1-\phi)(1-\beta \phi)}\left(\hat{R}_{t}^{*}-\hat{R}_{t-1}^{*}\right)^{2} \\
+\frac{1}{2}\left[\hat{R}_{t}-\left(i_{t}+\mu_{t}+u_{t}\right)\right]^{2}+\frac{1}{2}\left(\hat{R}_{t}^{*}\right)^{2} \\
+\frac{1-v}{4 v}\left\{\left[\hat{R}_{t}-\left(i_{t}+\mu_{t}+u_{t}\right)\right]+\hat{R}_{t}^{*}\right\}^{2}
\end{array}\right\} .
$$

\subsection{Cooperation vs Noncooperation in the Short-Run}

We first define the optimal allocations in the linear quadratic framework as follows. 
Definition 1 The optimal cooperative allocation is the sequence of endogenous variables $\left\{\hat{R}_{t}, \hat{R}_{t}^{*}, i_{t}, i_{t}^{*}, \hat{Y}_{t}\right\}$ that minimizes (45) under the constraints (25), (26), and (30), given the sequence of shocks $\left\{u_{t}, z_{t}, \mu_{t}\right\}$ and the initial conditions: $\hat{R}_{0}$ and $\hat{R}_{0}^{*}$.

Definition 2 The optimal noncooperative allocation is the sequence of endogenous variables $\left\{\hat{R}_{t}, \hat{R}_{t}^{*}, i_{t}, i_{t}^{*}, \hat{Y}_{t}\right\}$, that minimizes (49) under the constraints (25), (26), and (30), given the sequence of the foreign policy interest rate $i_{t}^{*}$, shocks $\left\{u_{t}, \mu_{t}, z_{t}\right\}$ and the initial conditions: $\hat{R}_{0}$ and $\hat{R}_{0}^{*}$, and that minimizes (51) under the constraints (25), (26), and (30), given the sequence of the domestic policy interest rate $i_{t}$, shocks $\left\{u_{t}, z_{t}, \mu_{t}\right\}$ and the initial conditions: $\hat{R}_{0}$ and $\hat{R}_{0}^{*}$.

Note that parameters in equations (25), (26) and (30) do not rely on steady state values. Also, regarding the loss functions in (45), (49) and (51), the difference in steady states only matters for the parameters before the summation as in (46), which can be ignored when computing the optimal monetary policy. Therefore, even though the Ramsey steady states are different between cooperation and noncooperation, optimal responses are not affected by this difference.

Below, we describe how the optimal monetary policy under both cooperation and noncooperation will react to the technology shock, the loan premium shock and the markup shock, respectively.

\subsubsection{Technology Shock}

Note that the technology shock $z_{t}$ is not included in the loss functions under both cooperation and noncooperation, as shown in equations (45), (49) and (51). This fact implies that the level of loan rates or loan inflation rates, that the central banks aim to achieve, are independent from the technology shock. In a standard new Keynesian model, due to sticky prices, the technology shock alters the natural rate, namely the output under the flexible price equilibrium. Therefore, the output gap, which is defined as the difference in output between the sticky and flexible price equilibria and thus the central banks aim to minimize, also shifts as the technology shock changes. In contrast, in our model, due 
to the flexibility in price settings, the technology shock does not change the output gap. Thus, for the central bank, it is optimal to stabilize fluctuations in loan rates determined by equations (25) and (26). These equations do not contain the technology shock as the component of marginal costs for supplying loans.

Under both cooperation and noncooperation, it is optimal to achieve financial stability, namely, completely stabilizing the fluctuations in loan rates in both domestic and foreign countries. Any fluctuations in output $\hat{Y}_{t}$ according to equation (30) under $\hat{R}_{t}=\hat{R}_{t}^{*}=0$, namely,

$$
\hat{Y}_{t}=\frac{1}{2 v} z_{t}
$$

are optimal and should not be corrected by policy actions.

\subsubsection{Loan Premium Shock}

Contrary to the technology shock, the loan premium shock is included in the loss function in the foreign country as in equation (51) as well as in the domestic loan rate Phillips curve in equation (25). Despite this, the loan premium shock does not require policy cooperation either.

Under cooperation, since the loan premium shock is not included in the global loss function in equation (45), central banks in both countries should aim to achieve complete financial stability as $\hat{R}_{t}=\hat{R}_{t}^{*}=0$. This can be achieved by setting the domestic policy interest rate to eliminate the domestic loan premium shock in the domestic loan Phillips curve in equation (25) such that $i_{t}=-u_{t}$.

Under noncooperation, the domestic central bank aims to completely stabilize loan rates since the loss function does not contain the loan premium shock. To achieve this, again, the domestic policy rate is set to eliminate the loan premium shock. By doing so, loan rates are completely stabilized, since the marginal costs for supplying domestic loans in equation (25) are not fluctuating. Although the loan premium shock is included in the foreign loss function in equation (51), the domestic policy interest rate is not controllable by the foreign central bank. Consequently, the complete stabilization of loan rates by the domestic central bank suffices to achieve the optimal allocations. 
Figure 2: Optimal Responses to Markup Shock: $v=2$
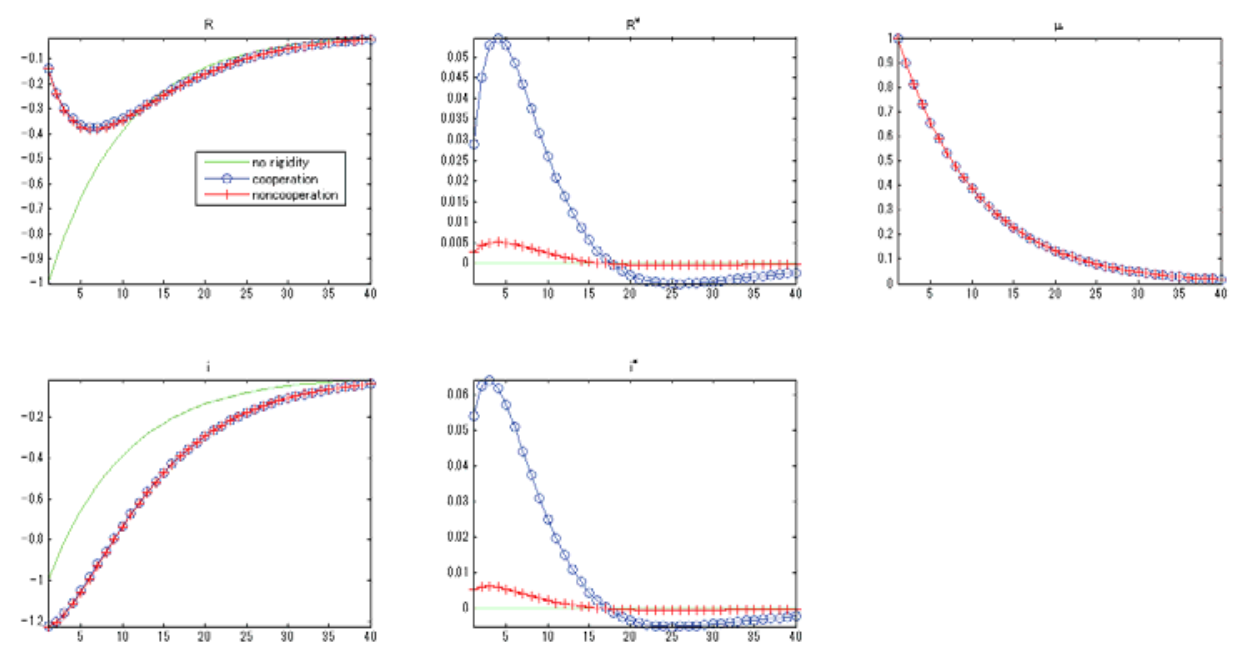

\subsubsection{Markup Shock}

The optimal responses to the markup shock $\mu_{t}$ under both cooperation and noncooperation are shown in Figures 2 and 3. The markup shock follows $\operatorname{AR}(1)$ process with a parameter of 0.9. Responses to shocks are derived under commitment together with the assumption that the initial endogenous state variables are set at their optimal steady state values. ${ }^{26}$ The parameters in Table 1 are again employed, but for the coefficient of the relative risk aversion $v$, we examine two values; figures 2 and 3 shows those when $v=2$, and $v=0.5$, respectively.

Green lines are the optimal responses when there are no rigidities in loan rate settings. By linearizing the optimality conditions of the Ramsey problem and assuming no rigidities in loan interest rates, namely $\phi=0$, the optimal dynamics without loan rate stickiness under both cooperation and noncooperation are derived as follows:

$$
\begin{gathered}
\hat{R}_{f, t}=-\mu_{t}, \\
\hat{R}_{f, t}^{*}=0, \\
i_{f, t}=-u_{t}-2 \mu_{t},
\end{gathered}
$$

\footnotetext{
${ }^{26}$ This is the timeless optimal monetary policy in the terminology of King and Wolman (1999).
} 
Figure 3: Optimal Responses to Markup Shock: $v=0.5$
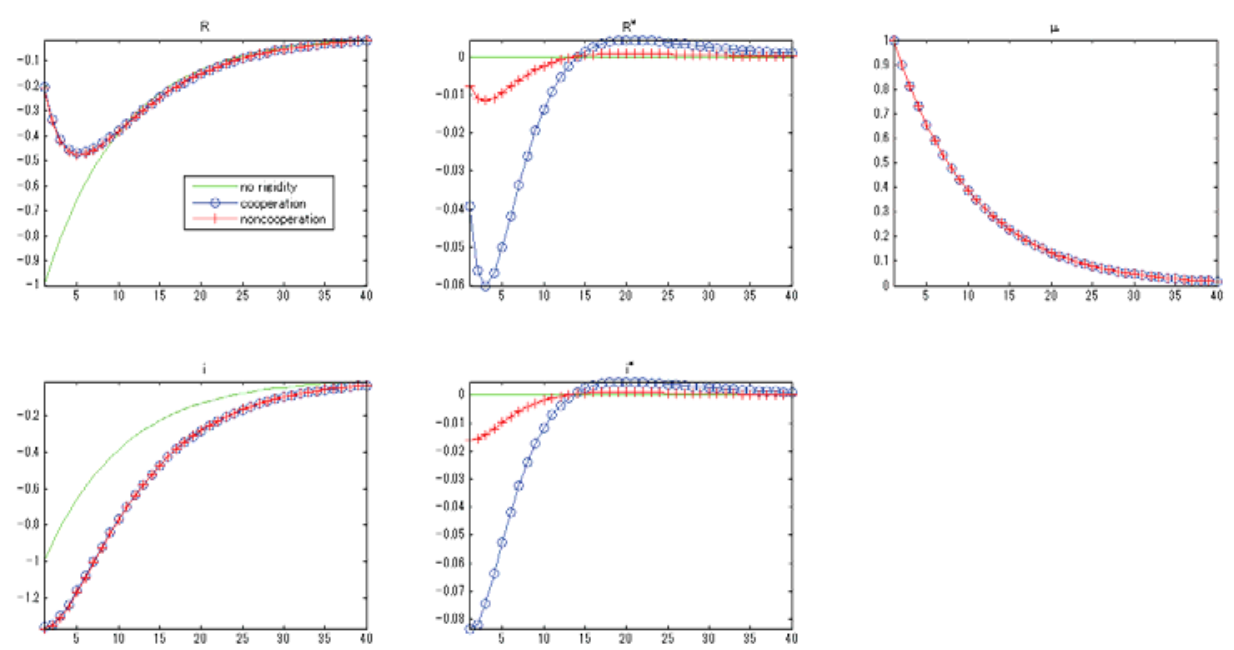

$$
i_{f, t}^{*}=0,
$$

and

$$
\hat{Y}_{f, t}=\frac{1}{2 v} z_{t} .
$$

There is no difference in the optimal responses under flexible loan settings between cooperation and noncooperation. Although steady states are different, central banks under both cooperation and noncooperation have the same goal for their stabilization policies to structural shocks. In addition, only the markup shock changes the target level of loan interest rates as explicit in equation (52). The social loss functions under both cooperation and noncooperation consist only of loan interest rates. Thus, the optimal policy is to completely stabilize fluctuations in loan interest rates in the presence of the loan premium or the technology shock. These equations also explain why there is no difference in optimal policies between cooperation and noncooperation for the technology or the loan premium shock.

When a negative shock is applied to the domestic markup, equation (52) implies that in the absence of staggered loan contracts, domestic loan rates should be decreased immediately. Note that as equation (16) implies, this is a shock to reduce the markup. Yet, as implicit in equations (20) and (22), and explicit in loss functions in (45), (49) 
and (51), fluctuations in loan interest rates results in the resource costs. Consequently, under both cooperation and noncooperation, in order to avoid resource costs stemming from loan rate dispersions, loan interest rates gradually change after a negative markup shock

Under cooperation, when $v=2$, foreign loan and policy interest rates move in the opposite direction to domestic interest rates. On the other hand, when $v=0.5$, they both move in the same direction. In this model, since the intratemporal elasticity of substitution between domestic and foreign goods is set at unity as in equation (7), the coefficient of relative risk aversion solely determines whether goods produced in the two countries are Edgeworth complements or substitutes. ${ }^{27}$ When $v>1(v<1)$, for instance, the intertemporal elasticity of substitution becomes lower (higher) than the intratemporal elasticity of substitution. In this situation, home goods and foreign goods are Edgeworth substitutes (complements). Consequently, output in the domestic country moves in the opposite (same) direction to that of the foreign country.

This mechanism can be understood by analyzing the relationship between marginal costs and the terms of trade. By combining the resource constraint with the labor market equilibrium condition, only marginal costs with the presence of the markup shock are given by

$$
M C_{t}=\frac{w_{t}}{P_{H, t}}=\left(\frac{l_{t}}{\Delta_{t}}\right)^{v} \operatorname{ToT}_{t}^{\psi(v-1)}
$$

where $\psi$ is $0.5 .^{28}$ Improvements of the terms of trade have two opposing effects to marginal costs. First, by affecting output prices, improvements in the terms of trade directly decrease marginal costs in the home country. Second, these result in the production switching from domestically produced to foreign-produced goods. Given domestic output, this requires a rise in output in the foreign country. Total consumption rises in both countries, and due to risk sharing, both domestic and foreign consumption rise by the

\footnotetext{
${ }^{27}$ For more detail on this point, see, for example, Tille (2001), Clarida, Gali, and Gertler (2002), Benigno and Benigno (2003, 2006), Fujiwara, Nakajima, Sudo, and Teranishi (2013) and Fujiwara and Ueda (2013). When $v=1$, namely with the log utility, two countries become insular and thre is no spillover between the two countries.

${ }^{28}$ Equations (62), (69), (74) and (88) in Appendix A are used.
} 
same amount. A rise in domestic consumption raises marginal costs in the home country, and to offset the rise in prices, home employment must decrease. In the terminology of Clarida, Gali, and Gertler (2002), the former is the terms of trade effects while the latter is the risk sharing effects. For example, when $v>1$, the latter dominates the former channel. A negative shock to the markup in the domestic country reduces domestic loan interest rates. As shown in equation (39), this worsens the terms of trade for the domestic country and therefore improves the foreign terms of trade. The negative markup shock spills over to the foreign country as if it were a positive shock to marginal costs. Consequently, in this case, foreign loan rates should increase.

When loan rates are revised infrequently, significant differences between cooperation (blue lines) and noncooperation (red lines) are observed in the responses of foreign loan and policy interest rates. This is because under noncooperation, central banks in both countries are unable to internalize the terms of trade externality as discussed above and in such papers as Corsetti and Pesenti (2001), Tille (2001), and Benigno and Benigno (2003, 2006). Through the relationship of domestic marginal costs and the terms of trade in equation (53), when $v>1(v<1)$, increase (decrease) in policy interest rates in the foreign country alleviate the problem of the domestic country stemming from the negative markup shock. Under noncooperation, however, the terms of trade externality is not internalized. Foreign monetary policy only reacts to the spillover effects on foreign marginal costs from the markup shock in the domestic country. As a result, under noncooperation, the reactions of foreign variables to the domestic markup shock are lessened.

The divergence of equilibrium responses between cooperation and noncooperation to the markup shock is not a new finding and has already been reported in Benigno and Benigno (2006). The necessity of cooperation in the presence of the markup shock does not stem from financial market imperfections, but simply from monopolistic competition in the goods market. Financial frictions per se do not require policy cooperation to dynamically improve social welfare over business cycles.

Now, let us check whether inward-looking policy can replicate the optimal allocations 
in the open economy subject to financial frictions. First order conditions from the welfare maximization (the social loss minimization) problem under cooperation are

$$
\frac{\phi \sigma\left[\left(\hat{R}_{t}-\hat{R}_{t-1}\right)-\beta\left(\mathbb{E}_{t} \hat{R}_{t+1}-\hat{R}_{t}\right)\right]}{(1-\phi)(1-\beta \phi)}+\frac{(1+v)\left(\hat{R}_{t}+\mu_{t}\right)+(1-v) \hat{R}_{t}^{*}}{2 v}=0,
$$

and

$$
\frac{\phi \sigma\left[\left(\hat{R}_{t}^{*}-\hat{R}_{t-1}^{*}\right)-\beta\left(\mathbb{E}_{t} \hat{R}_{t+1}^{*}-\hat{R}_{t}^{*}\right)\right]}{(1-\phi)(1-\beta \phi)}+\frac{(1-v)\left(\hat{R}_{t}+\mu_{t}\right)+(1+v) \hat{R}_{t}^{*}}{2 v}=0 .
$$

These two determine the optimal paths of loan rates in both domestic and foreign countries, $\hat{R}_{t}$ and $\hat{R}_{t}^{*}$, to the markup shock. By substituting out $\hat{R}_{t}^{*}$ from equation (54) and $\hat{R}_{t}$ in equation (55), we can derive

$$
\begin{aligned}
& 2[v \phi \sigma(1-\mathrm{L})(\mathrm{L}-\beta)-(1+v)(1-\phi)(1-\beta \phi) \mathrm{L}] \hat{R}_{t} \\
& +(1+v)(1-\phi)(1-\beta \phi) \mathrm{L} \mu_{t}=0,
\end{aligned}
$$

and

$$
\begin{aligned}
& 2[v \phi \sigma(1-\mathrm{L})(\beta-\mathrm{L})-(1+v)(1-\phi)(1-\beta \phi) \mathrm{L}] \hat{R}_{t}^{*} \\
& -(1-v)(1-\phi)(1-\beta \phi) \mathrm{L} \mu_{t}=0,
\end{aligned}
$$

where L denotes the lag operator. Equations (56) and (57) display the targeting rules for domestic and foreign central banks respectively. ${ }^{29}$ There, the equilibrium path of domestic (foreign) loan rates is solely determined by past domestic (foreign) loan rates and markup shocks. Thus, over business cycles, inward-looking financial stability, namely eliminating the inefficient fluctuation of the loan premium in its own country, is the optimal monetary policy in the open economy irrespective of the existence of the policy coordination. Divine coincidence in the terminology of Corsetti, Dedola, and Leduc (2010) holds even in this open economy with financial frictions. ${ }^{30}$

\footnotetext{
${ }^{29}$ Compared to the inward-looking targeting rules in Benigno and Benigno (2006), equations (56) and (57) are more complicated. This is because the staggered loan contracts require not only the stabilization of loan inflation rates but also the level of loan rates, as can be understood from the loss functions in equations (45), (49) and (51).

${ }^{30}$ Corsetti, Dedola, and Leduc (2010) define divine coincidence in open economy as the situation
} 


\subsection{International Banking}

So far, we have abstracted international lending and borrowing. Financial globalization has been expanding quite rapidly. We can easily observe this trend from recent financial and economic developments. Gadanecz (2004), McGuire and Tarashev (2006), and Lane and Milesi-Ferretti $(2007,2008)$ formally show that more funds from foreign countries are flowing into the domestic financial markets of other countries. In this subsection, we extend our model to incorporate international lending and borrowing. Two cases will be examined, namely, international funding and international lending and borrowing.

\subsubsection{International Funding}

As equation (11) implies, domestic private banks borrow solely from the domestic central bank. Assume instead that private bank $h$ can now borrow $\alpha$ portion from the domestic central bank, but $1-\alpha$ portion also from the foreign central bank. Then, the profit defined in equation (11) can be re-written as

$$
\Pi_{t}^{B}(h)=q_{t}(h)\left[(1+\tau) R_{t}(h)-\alpha\left(1+i_{t}\right)-(1-\alpha) \mathbb{E}_{t} \frac{S_{t+1}}{S_{t}}\left(1+i_{t}^{*}\right)\right] .
$$

The complete international financial market implies the UIP (uncovered interest rate parity) condition:

$$
1+i_{t}=\mathbb{E}_{t} \frac{S_{t+1}}{S_{t}}\left(1+i_{t}^{*}\right) \exp \left(\varepsilon_{t}\right),
$$

where we add the so-called UIP shock $\varepsilon_{t}$, whose importance has been emphasized by many empirical studies on international macroeconomics, such as Lubik and Schorfheide (2006). By combining equations (58) and (59), we have the modified profit equation under international lending and borrowing:

$$
\Pi_{t}^{B}(h)=q_{t}(h)\left\{(1+\tau) R_{t}(h)-\left(1+i_{t}\right)\left[\alpha+\frac{1-\alpha}{\exp \left(\varepsilon_{t}\right)}\right]\right\} .
$$

where inward looking policy can replicate the equilibrium under cooperation. Blanchard and Galí (2007) introduce the concept of divine coincidence in closed economy for the situation where price stability is the optimal policy. This is because the differences in the allocations between the Pareto and the flexible price equilibrium are constant and cannot be affected by policy. If it is time-varying and can be controlled by policy, such a situation is termed as real imperfections. 
Our results so far will not change even when the private banks can borrow internationally. Furthermore, the UIP shock works similarly to the loan premium shock. Therefore, it will not require policy cooperation to improve global welfare.

\subsubsection{International Lending and Borrowing}

Next, let us consider the situation where firms can borrow internationally. Suppose that domestic firms borrow $\alpha$ portion from the domestic private bank, but $1-\alpha$ portion also from the foreign private bank. ${ }^{31}$ Then, the profit equation of the domestic firm $h$ in equation (6) is re-written as

$$
\begin{aligned}
\Pi_{t}^{F}(h)= & (1+\tau)\left[p_{t}(h) y_{t}(h)+S_{t} p_{t}^{*}(h) y_{t}^{*}(h)\right] \\
& -\alpha R_{t}(h) w_{t}(h) l(h) \\
& -(1-\alpha) \mathbb{E}_{t} \frac{S_{t+1}}{S_{t}} R_{t}^{*}(h) w_{t}(h) l_{t}(h) .
\end{aligned}
$$

The second terms can be transformed into

$$
\alpha R_{t}(h) w_{t}(h) l(h)=\alpha M U_{t}^{R}(h)\left(1+i_{t}\right) w_{t}(h) l(h) \exp \left(u_{t}\right)
$$

while, by using equation (59), the third term can be written as

$$
(1-\alpha) \mathbb{E}_{t} \frac{S_{t+1}}{S_{t}} R_{t}^{*}(h) w_{t}(h) l_{t}(h)=(1-\alpha) M U_{t}^{R^{*}}(h)\left(1+i_{t}\right) w_{t}(h) l_{t}(h) \exp \left(\varepsilon_{t}\right) .
$$

$M U_{t}^{R}(h)$ and $M U_{t}^{R^{*}}(h)$ are time-varying markups for lending rates to domestic firm $h$ stemming from monopolistic competition and staggered loan contracts. As long as the UIP holds and the foreign bank lends to domestic firms in the foreign currency unit, the funding rate turns out to be the same as the domestic saving rate irrespective of international or domestic lending. International lending and borrowing do not alter the nature of the optimal monetary policy under both cooperation and noncooperation discussed in this paper. ${ }^{32}$

\footnotetext{
${ }^{31}$ For detailed analysis on this issue, see our working version of this paper (Fujiwara and Teranishi, 2009).

${ }^{32}$ The working paper version of this paper (Fujiwara and Teranishi, 2009) also considers international
} 


\section{Conclusion}

In this paper, by using a simple NOEM model with financial friction, we show that there are long-run gains in cooperation but that financial frictions per se do not require policy cooperation to dynamically improve social welfare over business cycles. Long-run gains arise even with the log utility, where the two countries become dynamically insular. In addition, inward-looking financial stability, namely eliminating inefficient fluctuations of the loan premium, turns out to be the optimal monetary policy in an open economy irrespective of the existence of policy coordination.

In order to understand the implications of financial frictions for policy cooperation, we employ a simple financial system consisting only of cost channel, monopoly power by banks and staggered loan contracts. Recently, there have been many attempts to positively analyze the role of financial frictions with more detailed modeling of financial sectors, following such studies as Kiyotaki and Moore (1997), Bernanke, Gertler, and Gilchrist (1999), Gertler and Kiyotaki (2010), or Gertler and Karadi (2011). Optimal monetary policy analysis together with such a complex banking sector becomes increasingly difficult with the existence of the endogenous state variables. ${ }^{33}$ Will this extension change our main results? This issue is left for future research.

lending for domestic firms in the domestic currency. There, for example, the profit equation of the domestic firm $h$ can be written as

$$
\Pi_{t}^{F}(h)=(1+\tau)\left[p_{t}(h) y_{t}(h)+S_{t} p_{t}^{*}(h) y_{t}^{*}(h)\right]-\left[\omega \mathbb{E}_{t} \frac{S_{t+1}}{S_{t}}+(1-\omega)\right] R_{t}^{*}(h) w_{t}(h) l_{t}(h) .
$$

while that foreign bank $h$ is

$$
\Pi_{t}^{B^{*}}(h)=q_{t}(h)\left\{(1+\tau)\left[\omega+(1-\omega) \mathbb{E}_{t} \frac{S_{t+1}}{S_{t}}\right] R_{t}^{*}(h)-i_{t}^{*}\right\} .
$$

The parameter $\omega$ determines how much is borrowed in the foreign currency unit. For example, if $\omega=1$, the domestic firm borrows in the foreign currency unit and therefore incurs all exchange rate risks.

Under this setting, the central bank under noncooperation has an additional incentive to appreciate domestic currency in order to reduce loan payments. Consequently, differences arise in the optimal allocations and prices between cooperative and non-cooperative regimes.

${ }^{33}$ To understand how the analysis with linear quadratic framework becomes complicated with the endogenous state variables, See, for example, Edge (2003). 


\section{References}

Andrés, Javier, and Óscar J. Arce (2009). "Banking competition, housing prices and macroeconomic stability." Banco de Espańa Working Papers 0830, Banco de Espańa.

Barth, Marvin J., and Valerie A. Ramey (2002). "The Cost Channel of Monetary Transmission." In NBER Macroeconomics Annual 2001, Volume 16, NBER Chapters, pp. 199-256. National Bureau of Economic Research, Inc.

Benigno, Gianluca, and Pierpaolo Benigno (2003). "Price Stability in Open Economies." Review of Economic Studies, 70(4), 743-764.

Benigno, Gianluca, and Pierpaolo Benigno (2006). "Designing targeting rules for international monetary policy cooperation." Journal of Monetary Economics, 53(3), 473-506.

Benigno, Pierpaolo, and Michael Woodford (2005). "Inflation Stabilization and Welfare: The Case of a Distorted Steady State." Journal of the European Economic Association, $3(6), 1185-1236$.

Benigno, Pierpaolo, and Michael Woodford (2012). "Linear-quadratic approximation of optimal policy problems." Journal of Economic Theory, 147(1), 1-42.

Berger, Allen N, and Gregory F Udell (1992). "Some Evidence on the Empirical Significance of Credit Rationing." Journal of Political Economy, 100(5), 1047-77.

Bernanke, Ben S., Mark Gertler, and Simon Gilchrist (1999). "The Financial Accelerator in a Quantitative Business Cycle Framework." In Handbook of Macroeconomics, edited by John. B. Taylor, and Michael Woodford, vol. 1 of Handbook of Macroeconomics, pp. 1341-1393. Elsevier.

Bilbiie, Florin O., Ippei Fujiwara, and Fabio Ghironi (2011). "Optimal Monetary Policy with Endogenous Entry and Product Variety." NBER Working Papers 17489, National Bureau of Economic Research, Inc. 
Blanchard, Olivier, and Jordi Galí (2007). "Real Wage Rigidities and the New Keynesian Model." Journal of Money, Credit and Banking, 39(s1), 35-65.

Calem, Paul S., Michael B. Gordy, and Loretta J. Mester (2006). "Switching costs and adverse selection in the market for credit cards: New evidence." Journal of Banking \& Finance, 30(6), 1653-1685.

Calvo, Guillermo A. (1983). "Staggered Prices in A Utility-Maximizing Framework." Journal of Monetary Economics, 12(3), 383-398.

Chari, V. V., Patrick J. Kehoe, and Ellen R. McGrattan (2007). "Business Cycle Accounting." Econometrica, 75(3), 781-836.

Christiano, Lawrence J., Martin Eichenbaum, and Charles L. Evans (1999). "Monetary Policy Shocks: What Have We Learned and to What End?." In Handbook of Macroeconomics, edited by John B. Taylor, and Michael Woodford, vol. 1 of Handbook of Macroeconomics, pp. 65-148. Elsevier.

Christiano, Lawrence J., Martin Eichenbaum, and Charles L. Evans (2005). "Nominal Rigidities and the Dynamic Effects of a Shock to Monetary Policy." Journal of Political Economy, 113(1), 1-45.

Clarida, Richard, Jordi Gali, and Mark Gertler (2002). "A Simple Framework for International Monetary Policy Analysis." Journal of Monetary Economics, 49(5), 879-904.

Cole, Harold L., and Maurice Obstfeld (1991). "Commodity trade and international risk sharing : How much do financial markets matter?." Journal of Monetary Economics, $28(1), 3-24$.

Cooley, Thomas F., and Vincenzo Quadrini (2003). "Common Currencies vs. Monetary Independence." Review of Economic Studies, 70(4), 785-806.

Corsetti, Giancarlo, Luca Dedola, and Sylvain Leduc (2010). "Optimal Monetary Policy in Open Economies." In Handbook of Monetary Economics, edited by Benjamin M. 
Friedman, and Michael Woodford, vol. 3 of Handbook of Monetary Economics, pp. 861-933. Elsevier.

Corsetti, Giancarlo, and Paolo Pesenti (2001). "Welfare And Macroeconomic Interdependence." The Quarterly Journal of Economics, 116(2), 421-445.

De Paoli, Bianca (2009). "Monetary Policy and Welfare in a Small Open Economy." Journal of International Economics, 77(1), 11-22.

Devereux, Michael B., and Charles Engel (2003). "Monetary Policy in the Open Economy Revisited: Price Setting and Exchange-Rate Flexibility." Review of Economic Studies, $70(4), 765-783$.

Edge, Rochelle M. (2003). "A Utility-Based Welfare Criterion in a Model with Endogenous Capital Accumulation." Finance and Economics Discussion Series 2003-66, Board of Governors of the Federal Reserve System (U.S.).

Fujiwara, Ippei, Tomoyuki Nakajima, Nao Sudo, and Yuki Teranishi (2013). "Global Liqudity Trap." Journal of Monetary Economics, 60(8).

Fujiwara, Ippei, and Yoshiyuki Nakazono (2013). "Optimal Monetary Policy with the Cost Channel Revisited." Discussion paper, mimeo.

Fujiwara, Ippei, and Yuki Teranishi (2009). "Financial Stability in Open Economies." IMES Discussion Paper Series 09-E-09, Institute for Monetary and Economic Studies, Bank of Japan.

Fujiwara, Ippei, and Yuki Teranishi (2011). "Real exchange rate dynamics revisited: A case with financial market imperfections." Journal of International Money and Finance, 30(7), 1562-1589.

Fujiwara, Ippei, and Kozo Ueda (2013). "The fiscal multiplier and spillover in a global liquidity trap." Journal of Economic Dynamics and Control, 37(7), 1264-1283.

Gadanecz, Blaise (2004). "The Syndicated Loan Market." BIS Quarterly Review. 
Gambacorta, Leonardo (2008). "How do banks set interest rates?." European Economic Review, 52(5), 792-819.

Gerali, Andrea, Stefano Neri, Luca Sessa, and Federico M. Signoretti (2010). "Credit and Banking in a DSGE Model of the Euro Area." Journal of Money, Credit and Banking, 42(s1), 107-141.

Gertler, Mark, and Peter Karadi (2011). "A model of unconventional monetary policy." Journal of Monetary Economics, 58(1), 17-34.

Gertler, Mark, and Nobuhiro Kiyotaki (2010). "Financial Intermediation and Credit Policy in Business Cycle Analysis." In Handbook of Monetary Economics, edited by Benjamin M. Friedman, and Michael Woodford, vol. 3 of Handbook of Monetary Economics, pp. 547-599. Elsevier.

Graham, Liam, and Stephen Wright (2007). "Nominal Debt Dynamics, Credit Constraints and Monetary Policy." The B.E. Journals of Macroeconomics, 7(1).

Gropp, Reint, and Anil K Kashyap (2010). "A New Metric for Banking Integration in Europe." In Europe and the Euro, NBER Chapters, pp. 219-246. National Bureau of Economic Research, Inc.

Hannan, Timothy H, and Allen N Berger (1991). "The Rigidity of Prices: Evidence from the Banking Industry." American Economic Review, 81(4), 938-45.

Kim, Jinill, Sunghyun Kim, Ernst Schaumburg, and Christopher A Sims (2008). "Calculating and using second-order accurate solutions of discrete time dynamic equilibrium models." Journal of Economic Dynamics and Control, 32(11), 3397-3414.

Kim, Jinill, and Sunghyun Henry Kim (2003). "Spurious welfare reversals in international business cycle models." Journal of International Economics, 60(2), 471-500.

Kim, Jinill, and Sunghyun Henry Kim (2007). "Two Pitfalls of Linearization Methods." Journal of Money, Credit and Banking, 39(4), 995-1001. 
King, Robert, and Alexander L. Wolman (1999). "What Should the Monetary Authority Do When Prices Are Sticky?.” In Monetary Policy Rules, NBER Chapters, pp. 349404. National Bureau of Economic Research, Inc.

Kiyotaki, Nobuhiro, and John Moore (1997). "Credit Cycles." Journal of Political Economy, 105(2), 211-45.

Kobayashi, Teruyoshi (2008). "Incomplete Interest Rate Pass-Through and Optimal Monetary Policy." International Journal of Central Banking, 4(3), 77-118.

Lane, Philip R., and Gian Maria Milesi-Ferretti (2007). "The External Wealth of National Mark II." Journal of International Economics, 73(2), 223-50.

Lane, Philip R., and Gian Maria Milesi-Ferretti (2008). "The Drivers of Financial Globalization." American Economic Review, 98(2), 327-32.

Lubik, Thomas, and Frank Schorfheide (2006). "A Bayesian Look at the New Open Economy Macroeconomics." In NBER Macroeconomics Annual 2005, Volume 20, NBER Chapters, pp. 313-382. National Bureau of Economic Research, Inc.

Mandelman, Federico S. (2010). "Business cycles and monetary regimes in emerging economies: A role for a monopolistic banking sector." Journal of International Economics, 81(1), 122-138.

Mandelman, Federico S. (2011). "Business Cycles and the Role of Imperfect Competition in the Banking System." International Finance, 14(1), 103-133.

McGuire, Patrick, and Nikola Tarashev (2006). "Tracking International Bank Flows." BIS Quarterly Review, 27(4).

Perri, Fabrizio, and Vincenzo Quadrini (2011). "International Recessions." NBER Working Papers 17201, National Bureau of Economic Research, Inc.

Ravenna, Federico, and Carl E. Walsh (2006). "Optimal monetary policy with the cost channel." Journal of Monetary Economics, 53(2), 199-216. 
Slovin, Myron B, and Marie Elizabeth Sushka (1983). "A Model of the Commercial Loan Rate." Journal of Finance, 38(5), 1583-96.

Smets, Frank, and Raf Wouters (2003). "An Estimated Dynamic Stochastic General Equilibrium Model of the Euro Area." Journal of the European Economic Association, $1(5), 1123-1175$.

Smets, Frank, and Rafael Wouters (2007). "Shocks and Frictions in US Business Cycles: A Bayesian DSGE Approach." American Economic Review, 97(3), 586-606.

Sorensen, Christoffer Kok, and Thomas Werner (2006). "Bank Interest Rate PassThrough in the Euro Area: A Cross Country Comparison." Working Paper Series 580, European Central Bank.

Steinsson, Jón (2008). "The Dynamic Behavior of the Real Exchange Rate in Sticky Price Models." American Economic Review, 98(1), 519-33.

Sutherland, Alan (2002). "A Simple Second-Order Solution Method for Dynamic General Equilibrium Models." Discussion Paper Series, Department of Economics 200211, Department of Economics, University of St. Andrews.

Teranishi, Yuki (2008). "Optimal Monetary Policy under Staggered Loan Contracts." IMES Discussion Paper Series 08-E-08 (forthcoming in Economic Journal), Institute for Monetary and Economic Studies, Bank of Japan.

Tille, Cedric (2001). "The Role of Consumption Substitutability in the International Transmission of Monetary Shocks." Journal of International Economics, 53(2), 421444.

van Leuvensteijn, Michiel, Christoffer Kok Sorensen, Jacob A. Bikker, and Adrian A.R.J.M. van Rixtel (2013). "Impact of bank competition on the interest rate pass-through in the euro area." Applied Economics, 45(11), 1359-1380.

Woodford, Michael (2003). Interest and Prices: Foundations of a Theory of Monetary Policy. Princeton: Princeton University Press. 
Woodford, Michael (2007). "Globalization and Monetary Control." In International Dimensions of Monetary Policy, NBER Chapters, pp. 13-77. National Bureau of Economic Research, Inc.

Yun, Tack (1996). "Nominal Price Rigidity, Money Supply Endogeneity, and Business Cycles." Journal of Monetary Economics, 37(2-3), 345-370.

Yun, Tack (2005). "Optimal Monetary Policy with Relative Price Distortions." American Economic Review, 95(1), 89-109. 


\section{Appendix A: Equilibrium Conditions}

\section{Consumers}

From the consumer's utility maximization problem given by equations (1) and (2), the intertemporal optimality condition is derived:

$$
C_{t}^{-v}=\beta\left(1+i_{t}\right) \mathbb{E}_{t}\left(\frac{C_{t+1}^{-v} P_{t}}{P_{t+1}}\right)
$$

and

$$
\frac{1}{1+i_{t}}=\mathbb{E}_{t}\left(X_{t, t+1}\right)
$$

Also, the optimality condition for differentiated labor supply is given by

$$
C_{t}^{v}=\frac{w_{t}(h)}{P_{t}}=\frac{w_{t}}{P_{t}}
$$

Linear dis-utility in labor supply results in a homogenous wage rate.

Similarly for the foreign country, we have

$$
\begin{gathered}
\left(C_{t}^{*}\right)^{-v}=\beta\left(1+i_{t}^{*}\right) \mathbb{E}_{t}\left[\frac{\left(C_{t+1}^{*}\right)^{-v} P_{t}^{*}}{P_{t+1}^{*}}\right], \\
\frac{1}{1+i_{t}^{*}}=\mathbb{E}_{t}\left(X_{t, t+1}\right) \frac{S_{t+1}}{S_{t}},
\end{gathered}
$$

and

$$
\left(C_{t}^{*}\right)^{v}=\frac{w_{t}^{*}\left(h^{*}\right)}{P_{t}^{*}}=\frac{w_{t}^{*}}{P_{t}^{*}},
$$

where $S_{t}$ denotes the nominal exchange rate. By combining (60), (61), (63) and (64), under the assumption where both countries are equally wealthy initially, the following international risk sharing condition determines the real exchange rate $e_{t}$.

$$
C_{t}^{v}=e_{t}\left(C_{t}^{*}\right)^{v}
$$

where

$$
e_{t}=\frac{S_{t} P_{t}^{*}}{P_{t}}
$$




\section{Final Goods Producers}

The cost minimization problem by the final goods producer leads to

$$
P_{H, t}=\psi P_{t} \frac{Y_{H, t}^{\psi-1} Y_{F, t}^{1-\psi}}{\psi^{\psi}(1-\psi)^{1-\psi}}=\psi P_{t} \frac{Y_{t}}{Y_{H, t}},
$$

and

$$
P_{F, t}=(1-\psi) P_{t} \frac{Y_{t}}{Y_{F, t}} .
$$

By plugging them into production function (7),

$$
P_{t}=P_{H, t}^{\psi} P_{F, t}^{1-\psi}
$$

By solving similar cost minimization problem on equation (8), the standard definition of aggregate price index and relative demands are derived as

$$
P_{H, t}=\left[\int_{0}^{1} p_{t}(h)^{1-\sigma} \mathrm{d} h\right]^{\frac{1}{1-\sigma}},
$$

and

$$
y_{t}(h)=\left[\frac{p_{t}(h)}{P_{H, t}}\right]^{-\sigma} Y_{H, t} .
$$

Similarly, in the foreign country,

$$
\begin{gathered}
Y_{F, t}^{*}=(1-\psi)\left(\frac{P_{F, t}^{*}}{P_{t}^{*}}\right)^{-1} Y_{t}^{*}, \\
Y_{H, t}^{*}=\psi\left(\frac{P_{H, t}^{*}}{P_{t}^{*}}\right)^{-1} Y_{t}^{*}, \\
P_{t}^{*}=\left(P_{H, t}^{*}\right)^{\psi}\left(P_{F, t}^{*}\right)^{1-\psi}, \\
P_{H, t}^{*}=\left[\int_{0}^{1} p_{t}^{*}(h)^{1-\sigma} \mathrm{d} h\right]^{\frac{1}{1-\sigma}},
\end{gathered}
$$

and

$$
y_{t}^{*}(h)=\left[\frac{p_{t}^{*}(h)}{P_{H, t}^{*}}\right]^{-\sigma} Y_{H, t}^{*}
$$




\section{Intermediated Goods Producers}

From the profit maximization problem in equation (6) by intermediate-goods producer $h$, together with equations (3) and (71), the optimal price setting conditions are derived as

$$
p_{t}(h)=\frac{\sigma R_{t}(h) w_{t}}{(1+\tau)(\sigma-1) \exp \left(z_{t}\right)} .
$$

Similarly, for the foreign firms,

$$
p_{t}^{*}\left(h^{*}\right)=\frac{\sigma R_{t}^{*}\left(h^{*}\right) w_{t}^{*}}{(1+\tau)(\sigma-1)}
$$

and the law of one price implies

$$
p_{t}\left(h^{*}\right)=S_{t} p_{t}^{*}\left(h^{*}\right)
$$

\section{Banks}

The loan demand is expressed by combining equations (3), (4), (5), (62), (70), (71), (75), (76) and (77) as

$$
q_{t}(h)=\frac{w_{t}}{\exp \left(z_{t}\right)}\left[\frac{R_{t}(h)}{R_{t}}\right]^{-\sigma}\left(Y_{H, t}+Y_{H, t}^{*}\right) .
$$

To maximize the profit maximization in equation (10) together with equation (79), the private bank optimally sets its loan rate $\tilde{R}_{t}$ to satisfy $\mathbb{E}_{t} \sum_{T=t}^{\infty}(\beta \phi)^{T-t} \frac{P_{t} C_{T}^{-v} w_{T} \exp \left(z_{t}\right)\left(Y_{H, T}+Y_{H, T}^{*}\right)}{P_{T} C_{t}^{-v} w_{t} \exp \left(z_{T}\right)\left(Y_{H, t}+Y_{H, t}^{*}\right)}\left(\frac{R_{t}}{R_{T}}\right)^{-\sigma-1}\left[\frac{\tilde{R}_{t}}{R_{t}} \frac{R_{t}}{R_{T}}-\frac{\sigma\left(1+i_{T}\right) u_{T}}{(1+\tau)(\sigma-1) R_{T}}\right]=0$.

From equation (29),

$$
\frac{\tilde{R}_{t}}{R_{t}}=\left[\frac{1-\phi\left(\frac{R_{t-1}}{R_{t}}\right)^{1-\sigma}}{1-\phi}\right]^{\frac{1}{1-\sigma}} .
$$

By combining equations (80) and (81),

$$
\left[\frac{1-\phi\left(\frac{R_{t-1}}{R_{t}}\right)^{1-\sigma}}{1-\phi}\right]^{\frac{1}{1-\sigma}} F_{t}=K_{t}
$$


where

$$
\begin{aligned}
F_{t} & \equiv \mathbb{E}_{t} \sum_{T=t}^{\infty}(\beta \phi)^{T-t} \frac{P_{t} C_{T}^{-v} w_{T} \exp \left(z_{t}\right)\left(Y_{H, T}+Y_{H, T}^{*}\right)}{P_{T} C_{t}^{-v} w_{t} \exp \left(z_{T}\right)\left(Y_{H, t}+Y_{H, t}^{*}\right)}\left(\frac{R_{t}}{R_{T}}\right)^{-\sigma} \\
& =1+\beta \phi \mathbb{E}_{t} \frac{P_{t} C_{t+1}^{-v} w_{t+1} \exp \left(z_{t}\right)\left(Y_{H, t+1}+Y_{H, t+1}^{*}\right)}{P_{t+1} C_{t}^{-v} w_{t} \exp \left(z_{t+1}\right)\left(Y_{H, t}+Y_{H, t}^{*}\right)}\left(\frac{R_{t}}{R_{t+1}}\right)^{-\sigma} F_{t+1},
\end{aligned}
$$

and

$$
\begin{aligned}
K_{t} & \equiv \mathbb{E}_{t} \sum_{T=t}^{\infty}(\beta \phi)^{T-t} \frac{P_{t} C_{T}^{-v} w_{T} \exp \left(z_{t}\right)\left(Y_{H, T}+Y_{H, T}^{*}\right)}{P_{T} C_{t}^{-v} w_{t} \exp \left(z_{T}\right)\left(Y_{H, t}+Y_{H, t}^{*}\right)}\left(\frac{R_{t}}{R_{T}}\right)^{-\sigma-1} \frac{\sigma\left(1+i_{T}\right) u_{T}}{(1+\tau)(\sigma-1) R_{T}}(84) \\
& =\frac{\sigma\left(1+i_{t}\right) \exp \left(u_{t}\right)}{(1+\tau)(\sigma-1) R_{t}}+\mathbb{E}_{t} \beta \phi \frac{P_{t} C_{t+1}^{-v} w_{t+1} \exp \left(z_{t}\right)\left(Y_{H, t+1}+Y_{H, t+1}^{*}\right)}{P_{t+1} C_{t}^{-v} w_{t} \exp \left(z_{t+1}\right)\left(Y_{H, t}+Y_{H, t}^{*}\right)}\left(\frac{R_{t}}{R_{t+1}}\right)^{-\sigma-1} K_{t+1} .
\end{aligned}
$$

Similarly, for loan rate settings in the foreign country,

$$
\left[\frac{1-\phi\left(\frac{R_{t-1}^{*}}{R_{t}^{*}}\right)^{1-\sigma}}{1-\phi}\right]^{\frac{1}{1-\sigma}} F_{t}^{*}=K_{t}^{*},
$$

where

$$
F_{t}^{*}=1+\beta \phi \mathbb{E}_{t} \frac{P_{t}^{*}\left(C_{t+1}^{*}\right)^{v} w_{t+1}^{*}\left(Y_{F, t+1}+Y_{F, t+1}^{*}\right)}{P_{t+1}^{*}\left(C_{t}^{*}\right)^{v} w_{t}^{*}\left(Y_{F, t}+Y_{F, t}^{*}\right)}\left(\frac{R_{t}^{*}}{R_{t+1}^{*}}\right)^{-\sigma} F_{t+1}^{*}
$$

and

$$
K_{t}^{*}=\frac{\sigma\left(1+i_{t}^{*}\right)}{(1+\tau)(\sigma-1) R_{t}^{*}}+\mathbb{E}_{t} \beta \phi \frac{P_{t}^{*}\left(C_{t+1}^{*}\right)^{-v} w_{t+1}^{*}\left(Y_{F, t+1}+Y_{F, t+1}^{*}\right)}{P_{t+1}^{*}\left(C_{t}^{*}\right)^{-v} w_{t}^{*}\left(Y_{F, t}+Y_{F, t}^{*}\right)}\left(\frac{R_{t}^{*}}{R_{t+1}^{*}}\right)^{-\sigma-1} K_{t+1}^{*} .
$$

\section{Aggregation}

With equations (3), (5), (29), (67), (70), (73), (71), (76) and (77),

$$
\psi \Delta_{t}\left(\frac{P_{t} Y_{t}}{P_{H, t}}+\frac{P_{t}^{*} Y_{t}^{*}}{P_{H, t}^{*}}\right)=\exp \left(z_{t}\right) l_{t}
$$

where

$$
l_{t} \equiv \int_{0}^{1} l_{t}(h) \mathrm{d} h
$$


By using equations (29) and (81), this can be expressed as a dynamic equation.

$$
\begin{aligned}
\Delta_{t} & \equiv \int_{0}^{1}\left[\frac{R_{t}(h)}{R_{t}}\right]^{-\sigma} \mathrm{d} h \\
& =(1-\phi)\left[\frac{1-\phi\left(\frac{R_{t-1}}{R_{t}}\right)^{1-\sigma}}{1-\phi}\right]^{\frac{\sigma}{\sigma-1}}+\phi\left(\frac{R_{t-1}}{R_{t}}\right)^{-\sigma} \Delta_{t-1} .
\end{aligned}
$$

Similarly for the foreign country,

$$
\left(\frac{P_{t} Y_{t}}{P_{F, t}}+\frac{P_{t}^{*} Y_{t}^{*}}{P_{F, t}^{*}}\right)(1-\psi) \Delta_{t}^{*}=l_{t}^{*},
$$

and

$$
\Delta_{t}^{*}=(1-\phi)\left[\frac{1-\phi\left(\frac{R_{t-1}^{*}}{R_{t}^{*}}\right)^{1-\sigma}}{1-\phi}\right]^{\frac{\sigma}{\sigma-1}}+\phi\left(\frac{R_{t-1}^{*}}{R_{t}^{*}}\right)^{-\sigma} \Delta_{t-1}^{*} .
$$

By combining (70), (77) and (29), the price index is related to marginal costs:

$$
P_{H, t}=\frac{\sigma w_{t} R_{t}}{(1+\tau)(\sigma-1) \exp \left(z_{t}\right)},
$$

With equation (5),

$$
P_{H, t}^{*}=\frac{\sigma w_{t} R_{t}}{S_{t}(1+\tau)(\sigma-1) \exp \left(z_{t}\right)} .
$$

Similarly, for price settings by the foreign firms,

$$
P_{F, t}^{*}=\frac{\sigma w_{t}^{*} R_{t}^{*}}{(1+\tau)(\sigma-1)}
$$

and

$$
P_{F, t}=\frac{S_{t} \sigma w_{t}^{*} R_{t}^{*}}{(1+\tau)(\sigma-1)}
$$

\section{System of Equations}

27 Equations (12), (13), (60), (62), (63), (65), (66), (67), (68), (69), (70), (73) (74), (82), (84), (83), (85) (87), (86), (88), (89), (90) (91), (92), (75), (94) and (95) determines dynamic paths of $\pi_{t}, \pi_{t}^{*}, \tilde{w}_{t}, \tilde{w}_{t}^{*}, e_{t}, Y_{H, t}, Y_{F, t}, Y_{t}, Y_{H, t}^{*}, Y_{F, t}^{*}, Y_{t}^{*}, R_{t}, F_{t}, K_{t}, R_{t}^{*}, F_{t}^{*}, K_{t}^{*}$, $l_{t}, \Delta_{t}, l_{t}^{*}, \Delta_{t}^{*}, p_{H, t}, p_{H, t}^{*}, p_{F, t}^{*}, p_{F, t}, C_{t}$ and $C_{t}^{*}$ under the optimal monetary policy for $i_{t}$ and $i_{t}^{*}$. 
Nominal variables are de-trended as

$$
\begin{aligned}
& \pi_{t} \equiv \frac{P_{t}}{P_{t-1}}, \tilde{w}_{t} \equiv \frac{w_{t}}{P_{t}}, \tilde{w}_{t}^{*} \equiv \frac{w_{t}^{*}}{P_{t}^{*}}, p_{H, t} \equiv \frac{P_{H, t}}{P_{t}}, p_{H, t}^{*} \equiv \frac{P_{H, t}^{*}}{P_{t}^{*}}, p_{F, t} \equiv \frac{P_{F, t}}{P_{t}}, p_{F, t}^{*} \equiv \frac{P_{F, t}^{*}}{P_{t}^{*}} \\
& C_{t}^{-v}=\beta\left(1+i_{t}\right) \mathbb{E}_{t}\left(\frac{C_{t+1}^{-v}}{\pi_{t+1}}\right) \\
& C_{t}^{v}=\tilde{w}_{t}, \\
& \left(C_{t}^{*}\right)^{-v}=\beta\left(1+i_{t}^{*}\right) \mathbb{E}_{t}\left[\frac{\left(C_{t+1}^{*}\right)^{-v}}{\pi_{t+1}^{*}}\right] \\
& \left(C_{t}^{*}\right)^{v}=\tilde{w}_{t}^{*} \\
& C_{t}^{v}=e_{t}\left(C_{t}^{*}\right)^{v} \\
& Y_{H, t}=\psi\left(p_{H, t}\right)^{-1} Y_{t}, \\
& Y_{F, t}=(1-\psi)\left(p_{F, t}\right)^{-1} Y_{t} \\
& Y_{F, t}^{*}=(1-\psi)\left(p_{F, t}^{*}\right)^{-1} Y_{t}^{*}, \\
& Y_{H, t}^{*}=\psi\left(p_{H, t}^{*}\right)^{-1} Y_{t}^{*}, \\
& {\left[\frac{1-\phi\left(\frac{R_{t-1}}{R_{t}}\right)^{1-\sigma}}{1-\phi}\right]^{\frac{1}{1-\sigma}} F_{t}=K_{t},} \\
& F_{t}=1+\beta \phi \mathbb{E}_{t} \frac{C_{t+1}^{-v} \tilde{w}_{t+1} \exp \left(z_{t}\right)\left(Y_{H, t+1}+Y_{H, t+1}^{*}\right)}{C_{t}^{-v} \tilde{w}_{t} \exp \left(z_{t+1}\right)\left(Y_{H, t}+Y_{H, t}^{*}\right)}\left(\frac{R_{t}}{R_{t+1}}\right)^{-\sigma} F_{t+1} \text {, } \\
& K_{t}=\frac{\sigma\left(1+i_{t}\right) \exp \left(u_{t}\right)}{(1+\tau)(\sigma-1) R_{t}}+\mathbb{E}_{t} \beta \phi \frac{C_{t+1}^{-v} \tilde{w}_{t+1} \exp \left(z_{t}\right)\left(Y_{H, t+1}+Y_{H, t+1}^{*}\right)}{C_{t}^{-v} \tilde{w}_{t} \exp \left(z_{t+1}\right)\left(Y_{H, t}+Y_{H, t}^{*}\right)}\left(\frac{R_{t}}{R_{t+1}}\right)^{-\sigma-1} K_{t+1} \text {, } \\
& {\left[\frac{1-\phi\left(\frac{R_{t-1}^{*}}{R_{t}^{*}}\right)^{1-\sigma}}{1-\phi}\right]^{\frac{1}{1-\sigma}} F_{t}^{*}=K_{t}^{*},} \\
& F_{t}^{*}=1+\beta \phi \mathbb{E}_{t} \frac{\left(C_{t+1}^{*}\right)^{-v} \tilde{w}_{t+1}^{*}\left(Y_{F, t+1}+Y_{F, t+1}^{*}\right)}{\left(C_{t}^{*}\right)^{-v} \tilde{w}_{t}^{*}\left(Y_{F, t}+Y_{F, t}^{*}\right)}\left(\frac{R_{t}^{*}}{R_{t+1}^{*}}\right)^{-\sigma} F_{t+1}^{*}, \\
& K_{t}^{*}=\frac{\sigma\left(1+i_{t}^{*}\right)}{(1+\tau)(\sigma-1) R_{t}^{*}}+\mathbb{E}_{t} \beta \phi \frac{\left(C_{t+1}^{*}\right)^{-v} \tilde{w}_{t+1}^{*}\left(Y_{F, t+1}+Y_{F, t+1}^{*}\right)}{\left(C_{t}^{*}\right)^{-v} \tilde{w}_{t}^{*}\left(Y_{F, t}+Y_{F, t}^{*}\right)}\left(\frac{R_{t}^{*}}{R_{t+1}^{*}}\right)^{-\sigma-1} K_{t+1}^{*},
\end{aligned}
$$




$$
\begin{aligned}
& \left(\frac{Y_{t}}{p_{H, t}}+\frac{Y_{t}^{*}}{p_{H, t}^{*}}\right) \psi \Delta_{t}=\exp \left(z_{t}\right) l_{t} \\
& \Delta_{t}=(1-\phi)\left[\frac{1-\phi\left(\frac{R_{t-1}}{R_{t}}\right)^{1-\sigma}}{1-\phi}\right]^{\frac{\sigma}{\sigma-1}}+\phi\left(\frac{R_{t-1}}{R_{t}}\right)^{-\sigma} \Delta_{t-1} \text {, } \\
& \left(\frac{Y_{t}}{p_{F, t}}+\frac{Y_{t}^{*}}{p_{F, t}^{*}}\right)(1-\psi) \Delta_{t}^{*}=\exp \left(z_{t}^{*}\right) l_{t}^{*} \\
& \Delta_{t}^{*}=(1-\phi)\left[\frac{1-\phi\left(\frac{R_{t-1}^{*}}{R_{t}^{*}}\right)^{1-\sigma}}{1-\phi}\right]^{\frac{\sigma}{\sigma-1}}+\phi\left(\frac{R_{t-1}^{*}}{R_{t}^{*}}\right)^{-\sigma} \Delta_{t-1}^{*}, \\
& p_{H, t}=\frac{\sigma \tilde{w}_{t} R_{t}}{(1+\tau)(\sigma-1) \exp \left(z_{t}\right)}, \\
& p_{H, t}^{*}=\frac{\sigma \tilde{w}_{t} R_{t}}{e_{t}(1+\tau)(\sigma-1) \exp \left(z_{t}\right)}, \\
& p_{F, t}^{*}=\frac{\sigma \tilde{w}_{t}^{*} R_{t}^{*}}{(1+\tau)(\sigma-1)}, \\
& p_{F, t}=\frac{e_{t} \sigma \tilde{w}_{t}^{*} R_{t}^{*}}{(1+\tau)(\sigma-1)} \text {, } \\
& C_{t}=Y_{t} \text {, } \\
& C_{t}^{*}=Y_{t}^{*}, \\
& 1=p_{H, t}^{\psi} p_{F, t}^{1-\psi},
\end{aligned}
$$

and

$$
1=\left(p_{H, t}^{*}\right)^{\psi}\left(p_{F, t}^{*}\right)^{1-\psi} .
$$

Under the assumption $\psi=0.5$, these collapse to equations (14) to (24). 


\section{Appendix B: Ramsey Policy}

\section{Cooperation}

The optimal monetary policy under cooperation is determined by equations below:

$$
\begin{aligned}
& 2 Y_{t}^{-v}+\frac{\lambda_{t}^{3}}{Y_{t-1}}-\mathbb{E}_{t} \frac{\beta \lambda_{t+1}^{3} Y_{t+1}}{Y_{t}^{2}}+\frac{2 v \lambda_{t}^{12} Y_{t}^{2 v-1} \exp \left(\mu_{t}\right) R_{t} R_{t}^{*}}{\exp \left(z_{t}\right)}\left[\frac{\sigma}{(1+\tau)(\sigma-1)}\right]^{2} \\
& -\frac{(1-v)(1+\tau)(\sigma-1) Y_{t}^{-v} \Delta_{t}}{\exp \left(\mu_{t}\right) \sigma R_{t}}-\frac{(1+\tau)(\sigma-1) Y_{t}^{-v} \Delta_{t}^{*}}{\sigma R_{t}^{*}}=0, \\
& -\lambda_{t}^{10}+\mathbb{E}_{t} \beta \lambda_{t+1}^{10} \phi \pi_{t+1}^{\sigma}-\frac{(1+\tau)(\sigma-1) Y_{t}^{1-v}}{\exp \left(\mu_{t}\right) \sigma R_{t}}=0, \\
& \frac{\lambda_{t}^{1}}{R_{t-1}}-\mathbb{E}_{t} \frac{\beta \lambda_{t+1}^{1} R_{t+1}}{R_{t}^{2}}+\frac{\lambda_{t}^{12} \exp \left(\mu_{t}\right) R_{t}^{*}}{\exp \left(z_{t}\right)}\left[\frac{\sigma}{(1+\tau)(\sigma-1)} Y_{t}^{v}\right]^{2}+\frac{(1+\tau)(\sigma-1) Y_{t}^{1-v} \Delta_{t}}{\sigma R_{t}^{2}}=0, \\
& -\lambda_{t}^{11}+\mathbb{E}_{t} \beta \lambda_{t+1}^{11} \phi\left(\pi_{t+1}^{*}\right)^{\sigma}-\frac{(1+\tau)(\sigma-1) Y_{t}^{1-v}}{\sigma R_{t}^{*}}=0 \\
& \frac{\lambda_{t}^{2}}{R_{t-1}^{*}}-\frac{\beta \lambda_{t+1}^{2} R_{t+1}^{*}}{\left(R_{t}^{*}\right)^{2}}+\frac{\lambda_{t}^{12} \exp \left(\mu_{t}\right) R_{t}}{\exp \left(z_{t}\right)}\left[\frac{\sigma}{(1+\tau)(\sigma-1)} Y_{t}^{v}\right]^{2}+\frac{(\sigma-1) Y_{t}^{1-v} \Delta_{t}^{*}}{\sigma\left(R_{t}^{*}\right)^{2}}=0, \\
& -\lambda_{t}^{1}+\lambda_{t-1}^{5}(\sigma-1) \phi g_{t}^{1-v} \pi_{t}^{\sigma-2} F_{t} \\
& +\lambda_{t}^{10} \phi \sigma\left[\pi_{t}^{\sigma-1} \Delta_{t-1}-\left(\frac{1-\phi \pi_{t}^{\sigma-1}}{1-\phi}\right)^{\frac{1}{\sigma-1}} \pi_{t}^{\sigma-2}\right]=0 \\
& -\lambda_{t}^{2}+\lambda_{t-1}^{8}(\sigma-1) \phi g_{t}^{1-v}\left(\pi_{t}^{*}\right)^{\sigma-2} F_{t}^{*} \\
& +\lambda_{t}^{11} \sigma \phi\left\{\left(\pi_{t}^{*}\right)^{\sigma-1} \Delta_{t-1}^{*}-\left[\frac{1-\phi\left(\pi_{t}^{*}\right)^{\sigma-1}}{1-\phi}\right]^{\frac{1}{\sigma-1}}\left(\pi_{t}^{*}\right)^{\sigma-2}\right\}=0 \text {, } \\
& -\lambda_{t}^{3}+\frac{\lambda_{t-1}^{5}(1-v) \phi \exp \left(z_{t}\right) g_{t}^{-v} \pi_{t}^{\sigma-1} F_{t}}{\exp \left(z_{t-1}\right)}+\lambda_{t-1}^{8}(1-v) \phi g_{t}^{-v}\left(\pi_{t}^{*}\right)^{\sigma-1} F_{t}^{*}=0, \\
& -\lambda_{t}^{5}+\lambda_{t-1}^{5} \phi g_{t}^{1-v} \pi_{t}^{\sigma-1}=0, \\
& -\lambda_{t}^{8}+\lambda_{t-1}^{8} \phi g_{t}^{1-v}\left(\pi_{t}^{*}\right)^{\sigma-1}=0, \\
& \lambda_{t}^{4}=0, \\
& \lambda^{6}=0 \text {, } \\
& \lambda_{t}^{7}=0,
\end{aligned}
$$




$$
\begin{aligned}
& \lambda^{9}=0, \\
& \lambda_{t}^{13}=1,
\end{aligned}
$$

and

$$
\lambda_{t}^{14}=1
$$

$\lambda^{i}$ denotes the Lagrange multiplier for the constraints (14) to (24), respectively.

\section{Noncooperation}

The optimal monetary policy under noncooperation is determined by equations below:

\section{Domestic}

$$
\begin{aligned}
& Y_{t}^{-v}+\frac{\tilde{\lambda}_{t}^{3}}{Y_{t-1}}-\mathbb{E}_{t} \frac{\beta \tilde{\lambda}_{t+1}^{3} Y_{t+1}}{Y_{t}^{2}}+\frac{2 v \tilde{\lambda}_{t}^{12} Y_{t}^{2 v-1} \exp \left(\mu_{t}\right) R_{t} R_{t}^{*}}{\exp \left(z_{t}\right)}\left[\frac{\sigma}{(1+\tau)(\sigma-1)}\right]^{2} \\
& -\frac{(1-v) Y_{t}^{-v} \Delta_{t}}{\exp \left(\mu_{t}\right) R_{t}}=0 \\
& -\tilde{\lambda}_{t}^{10}+\mathbb{E}_{t} \beta \tilde{\lambda}_{t+1}^{10} \phi \pi_{t+1}^{\sigma}-\frac{(1+\tau)(\sigma-1) Y_{t}^{1-v}}{\exp \left(\mu_{t}\right) \sigma R_{t}}=0, \\
& \frac{\tilde{\lambda}_{t}^{1}}{R_{t-1}}-\mathbb{E}_{t} \frac{\beta \tilde{\lambda}_{t+1}^{1} R_{t+1}}{R_{t}^{2}}+\frac{\tilde{\lambda}_{t}^{12} \exp \left(\mu_{t}\right) R_{t}^{*}}{\exp \left(z_{t}\right)}\left[\frac{\sigma}{(1+\tau)(\sigma-1)} Y_{t}^{v}\right]^{2}+\frac{Y_{t}^{1-v} \Delta_{t}}{\exp \left(\mu_{t}\right) R_{t}^{2}}=0, \\
& -\tilde{\lambda}_{t}^{11}+\mathbb{E}_{t} \beta \tilde{\lambda}_{t+1}^{11} \phi\left(\pi_{t+1}^{*}\right)^{\sigma}=0, \\
& \frac{\tilde{\lambda}_{t}^{2}}{R_{t-1}^{*}}-\mathbb{E}_{t} \frac{\beta \tilde{\lambda}_{t+1}^{2} R_{t+1}^{*}}{\left(R_{t}^{*}\right)^{2}}-\frac{\tilde{\lambda}_{t}^{9}\left(1+i_{t}^{*}\right) \exp \left(u_{t}^{*}\right)}{\left(R_{t}^{*}\right)^{2}}+\frac{\tilde{\lambda}_{t}^{12} R_{t}}{\exp \left(z_{t}\right)}\left[\frac{\sigma}{(1+\tau)(\sigma-1)} Y_{t}^{v}\right]^{2}=0 \text {, } \\
& -\tilde{\lambda}_{t}^{1}+\tilde{\lambda}_{t-1}^{5}(\sigma-1) \phi g_{t}^{1-v} \pi_{t}^{\sigma-2} F_{t} \\
& +\tilde{\lambda}_{t}^{10} \phi \sigma\left[\pi_{t}^{\sigma-1} \Delta_{t-1}-\left(\frac{1-\phi \pi_{t}^{\sigma-1}}{1-\phi}\right)^{\frac{1}{\sigma-1}} \pi_{t}^{\sigma-2}\right]=0 \text {, } \\
& -\tilde{\lambda}_{t}^{2}-\tilde{\lambda}_{t}^{7}\left[\frac{1-\phi\left(\pi_{t}^{*}\right)^{\sigma-1}}{1-\phi}\right]^{\frac{\sigma}{1-\sigma}} \frac{\phi\left(\pi_{t}^{*}\right)^{\sigma-2}}{1-\phi} F_{t}^{*}+\tilde{\lambda}_{t-1}^{8}(\sigma-1) \phi g_{t}^{1-v}\left(\pi_{t}^{*}\right)^{\sigma-2} F_{t}^{*} \\
& +\tilde{\lambda}_{t-1}^{9} \sigma \phi g_{t}^{1-v}\left(\pi_{t}^{*}\right)^{\sigma-1} K_{t}^{*} \\
& +\tilde{\lambda}_{t}^{11} \sigma \phi\left\{\left(\pi_{t}^{*}\right)^{\sigma-1} \Delta_{t-1}^{*}-\left[\frac{1-\phi\left(\pi_{t}^{*}\right)^{\sigma-1}}{1-\phi}\right]^{\frac{1}{\sigma-1}}\left(\pi_{t}^{*}\right)^{\sigma-2}\right\}=0,
\end{aligned}
$$




$$
\begin{gathered}
-\tilde{\lambda}_{t}^{3}+\tilde{\lambda}_{t-1}^{5}(1-v) \phi g_{t}^{-v} \pi_{t}^{\sigma-1} F_{t}+\tilde{\lambda}_{t-1}^{8}(1-v) \phi g_{t}^{-v}\left(\pi_{t}^{*}\right)^{\sigma-1} F_{t}^{*}+\tilde{\lambda}_{t-1}^{9}(1-v) \phi g_{t}^{-v}\left(\pi_{t}^{*}\right)^{\sigma} K_{t}^{*}=0 \\
-\tilde{\lambda}_{t}^{5}+\tilde{\lambda}_{t-1}^{5} \phi g_{t}^{1-v} \pi_{t}^{\sigma-1}=0 \\
-\tilde{\lambda}_{t}^{7}\left[\frac{1-\phi\left(\pi_{t}^{*}\right)^{\sigma-1}}{1-\phi}\right]^{\frac{1}{1-\sigma}}-\tilde{\lambda}_{t}^{8}+\tilde{\lambda}_{t-1}^{8} \phi g_{t}^{1-v}\left(\pi_{t}^{*}\right)^{\sigma-1}=0 \\
\tilde{\lambda}_{t}^{7}-\tilde{\lambda}_{t}^{9}+\tilde{\lambda}_{t-1}^{9} \phi g_{t}^{1-v}\left(\pi_{t}^{*}\right)^{\sigma}=0 \\
\tilde{\lambda}_{t}^{4}=0 \\
\tilde{\lambda}_{t}^{6}=0 \\
\tilde{\lambda}_{t}^{13}=1
\end{gathered}
$$

and

$$
\tilde{\lambda}_{t}^{14}=0
$$

$\tilde{\lambda}^{i}$ denotes the Lagrange multiplier for the constraints (14) to (24) for the domestic central bank's maximization problem.

\section{Foreign}

$$
\begin{aligned}
& Y_{t}^{-v}+\frac{\bar{\lambda}_{t}^{3}}{Y_{t-1}}-\mathbb{E}_{t} \frac{\beta \bar{\lambda}_{t+1}^{3} Y_{t+1}}{Y_{t}^{2}}+\frac{2 v \bar{\lambda}_{t}^{12} Y_{t}^{2 v-1} \exp \left(\mu_{t}\right) R_{t} R_{t}^{*}}{\exp \left(z_{t}\right) \exp \left(z_{t}^{*}\right)}\left[\frac{\sigma}{(1+\tau)(\sigma-1)}\right]^{2} \\
& -\frac{2(1-\psi)(1-v) Y_{t}^{-v} \Delta_{t}^{*}}{\gamma R_{t}^{*}}=0, \\
& -\bar{\lambda}_{t}^{10}+\mathbb{E}_{t} \beta \bar{\lambda}_{t+1}^{10} \phi \pi_{t+1}^{\sigma}=0, \\
& \frac{\bar{\lambda}_{t}^{1}}{R_{t-1}}-\mathbb{E}_{t} \frac{\beta \bar{\lambda}_{t+1}^{1} R_{t+1}}{R_{t}^{2}}-\frac{\bar{\lambda}_{t}^{6}\left(1+i_{t}\right) \exp \left(\mu_{t}\right) \exp \left(u_{t}\right)}{R_{t}^{2}}+\frac{\bar{\lambda}_{t}^{12} \exp \left(\mu_{t}\right) R_{t}^{*}}{\exp \left(z_{t}\right)}\left[\frac{\sigma Y_{t}^{v}}{(1+\tau)(\sigma-1)}\right]^{2}=0 \text {, } \\
& -\bar{\lambda}_{t}^{11}+\mathbb{E}_{t} \beta \bar{\lambda}_{t+1}^{11} \phi\left(\pi_{t+1}^{*}\right)^{\sigma}-\frac{(1+\tau)(\sigma-1) Y_{t}^{1-v}}{\sigma R_{t}^{*}}=0 \\
& +\bar{\lambda}_{t}^{2} \frac{1}{R_{t-1}^{*}}-\beta \bar{\lambda}_{t+1}^{2} \frac{R_{t+1}^{*}}{\left(R_{t}^{*}\right)^{2}}+\bar{\lambda}_{t}^{12}\left[\frac{\sigma Y_{t}^{v}}{(1+\tau)(\sigma-1)}\right]^{2} \frac{R_{t}}{\exp \left(z_{t}\right)}+\frac{(1+\tau)(\sigma-1) Y_{t}^{1-v} \Delta_{t}^{*}}{\sigma\left(R_{t}^{*}\right)^{2}}=0, \\
& -\bar{\lambda}_{t}^{2}+\bar{\lambda}_{t-1}^{8}(\sigma-1) \phi g_{t}^{1-v}\left(\pi_{t}^{*}\right)^{\sigma-2} F_{t}^{*} \\
& +\bar{\lambda}_{t}^{11} \sigma \phi\left\{\left(\pi_{t}^{*}\right)^{\sigma-1} \Delta_{t-1}^{*}-\left[\frac{1-\phi\left(\pi_{t}^{*}\right)^{\sigma-1}}{1-\phi}\right]^{\frac{1}{\sigma-1}}\left(\pi_{t}^{*}\right)^{\sigma-2}\right\}=0 \text {, }
\end{aligned}
$$




$$
\begin{gathered}
-\bar{\lambda}_{t}^{3}+\bar{\lambda}_{t-1}^{5}(1-v) \phi g_{t}^{-v} \pi_{t}^{\sigma-1} F_{t} \\
+\bar{\lambda}_{t-1}^{6}(1-v) \phi g_{t}^{-v} \pi_{t}^{\sigma} K_{t}+\bar{\lambda}_{t-1}^{8}(1-v) \phi g_{t}^{-v}\left(\pi_{t}^{*}\right)^{\sigma-1} F_{t}^{*}=0 \\
-\bar{\lambda}_{t}^{4}\left(\frac{1-\phi \pi_{t}^{\sigma-1}}{1-\phi}\right)^{\frac{1}{1-\sigma}}-\bar{\lambda}_{t}^{5}+\bar{\lambda}_{t-1}^{5} \phi g_{t}^{1-v} \pi_{t}^{\sigma-1}=0, \\
\bar{\lambda}_{t}^{4}-\bar{\lambda}_{t}^{6}+\bar{\lambda}_{t-1}^{6} \phi g_{t}^{1-v} \pi_{t}^{\sigma}, \\
-\bar{\lambda}_{t}^{8}+\bar{\lambda}_{t-1}^{8} \phi g_{t}^{1-v}\left(\pi_{t}^{*}\right)^{\sigma-1}=0 \\
\bar{\lambda}_{t}^{7}=0 \\
\bar{\lambda}_{t}^{9}=0 \\
\bar{\lambda}_{t}^{13}=0
\end{gathered}
$$

and

$$
\bar{\lambda}_{t}^{14}=1
$$

$\bar{\lambda}^{i}$ denotes the Lagrange multiplier for the constraints (14) to (24) for the foreign central bank's maximization problem.

\section{Ramsey Optimal Steady State}

\section{Cooperation}

The Ramsey optimal steady states under cooperation is as follows:

$$
\begin{gathered}
F=K=F^{*}=K^{*}=\frac{1}{1-\beta \phi}, \\
\Delta=\Delta^{*}=1, \\
1+i=1+i^{*}=\left[\frac{(1+\tau)(\sigma-1)}{\sigma}\right]^{2}, \\
Y=l=l^{*}=1, \\
R=R^{*}=\frac{(1+\tau)(\sigma-1)}{\sigma}, \\
\lambda^{1}=\lambda^{2}=\lambda^{3}=\lambda^{4}=\lambda^{5}=\lambda^{6}=\lambda^{7}=\lambda^{8}=\lambda^{9}=0, \\
\lambda^{10}=\lambda^{11}=\frac{1}{\beta \phi-1},
\end{gathered}
$$




$$
\lambda^{12}=-1
$$

and

$$
\lambda^{13}=\lambda^{14}=1 .
$$

\section{Noncooperation}

On the other hand, the Ramsey optimal steady states under noncooperative framework are as follows:

$$
\begin{aligned}
& F=K=F^{*}=K^{*}=\frac{1}{1-\beta \phi}, \\
& \Delta=\Delta^{*}=1, \\
& 1+i=1+i^{*}=(1+v)\left[\frac{(1+\tau)(\sigma-1)}{\sigma}\right]^{2} \text {, } \\
& Y=l=l^{*}=\left(\frac{1}{1+v}\right)^{\frac{1}{v}}, \\
& R=R^{*}=\frac{(1+v)(1+\tau)(\sigma-1)}{\sigma}, \\
& \tilde{\lambda}^{1}=\tilde{\lambda}^{2}=\tilde{\lambda}^{3}=\tilde{\lambda}^{4}=\tilde{\lambda}^{5}=\tilde{\lambda}^{6}=0, \\
& \tilde{\lambda}^{7}=(\phi-1)\left(\frac{1}{1+v}\right)^{\frac{1}{v}} \\
& \tilde{\lambda}^{8}=\left(\frac{1}{1+v}\right)^{\frac{1}{v}} \\
& \tilde{\lambda}^{9}=\tilde{\lambda}^{12}=-\left(\frac{1}{1+v}\right)^{\frac{1}{v}}, \\
& \tilde{\lambda}^{10}=\frac{1}{\beta \phi-1}\left(\frac{1}{1+v}\right)^{\frac{1}{v}} \text {, } \\
& \tilde{\lambda}^{11}=0, \\
& \tilde{\lambda}^{13}=1, \\
& \tilde{\lambda}^{14}=0, \\
& \bar{\lambda}^{1}=\bar{\lambda}^{2}=\bar{\lambda}^{3}=\bar{\lambda}^{7}=\bar{\lambda}^{8}=\bar{\lambda}^{9}=\bar{\lambda}^{10}=0, \\
& \bar{\lambda}^{4}=(\phi-1)\left(\frac{1}{1+v}\right)^{\frac{1}{v}},
\end{aligned}
$$




$$
\begin{gathered}
\bar{\lambda}^{5}=\left(\frac{1}{1+v}\right)^{\frac{1}{v}}, \\
\bar{\lambda}^{6}=\bar{\lambda}^{12}=-\left(\frac{1}{1+v}\right)^{\frac{1}{v}}, \\
\bar{\lambda}^{11}=\frac{1}{(\beta \phi-1)}\left(\frac{1}{1+v}\right)^{\frac{1}{v}}, \\
\bar{\lambda}^{13}=0,
\end{gathered}
$$

and

$$
\bar{\lambda}^{14}=1 .
$$




\section{Appendix C: Steady State Welfare Comparison}

When $v \neq 1$, welfare under cooperation is given by

$$
W_{C}=W_{C}^{*}=\frac{1}{1-\beta} \frac{v}{1-v},
$$

while that under noncooperation is

$$
W_{N}=W_{N}^{*}=\frac{1}{1-\beta}\left(\frac{1}{1+v}\right)^{\frac{1}{v}} \frac{2 v}{1-v} .
$$

Thus, the steady state welfare difference is

$$
\begin{aligned}
W_{C}-W_{N} & =\frac{1}{1-\beta} \frac{v}{1-v}-\frac{1}{1-\beta}\left(\frac{1}{1+v}\right)^{\frac{1}{v}} \frac{2 v}{1-v} \\
& =\frac{1}{1-\beta} \frac{v}{1-v}\left[1-2\left(\frac{1}{1+v}\right)^{\frac{1}{v}}\right]
\end{aligned}
$$

Equation (35) depicts that $\left(\frac{1}{1+v}\right)^{\frac{1}{v}}$ is always increasing in $v$ and it takes $\frac{1}{2}$ when $v=1$. Thus,

$$
W_{C}-W_{N}>0
$$

when

$$
0<v<1
$$

and

$$
v>1
$$

When $v=1$, welfare under cooperation is

$$
W_{C}=W_{C}^{*}=-\frac{1}{1-\beta},
$$

while that under noncooperation is

$$
\begin{aligned}
W_{N} & =W_{N}^{*}=\frac{1}{1-\beta}\left[\log \left(\frac{1}{2}\right)-\frac{1}{2}\right] \\
& =-\frac{1}{1-\beta}\left[\log (2)+\frac{1}{2}\right]<W_{C} .
\end{aligned}
$$




\section{Appendix D: Second Order Approximation of Loan Phillips Curve}

Here, the second order approximation of the loan Phillips curve in the domestic country will be described. First, we denote

$$
r_{t}^{*}=\frac{\tilde{R}_{t}}{R_{t}} .
$$

Then, equation (82) can be written as

$$
r_{t}^{*} F_{t}=K_{t},
$$

or

$$
\hat{r}_{t}^{*}+\hat{F}_{t}=\hat{K}_{t} .
$$

where $F_{t}$ and $K_{t}$ are slightly differently defined from equations (15) and (16):

$$
\begin{gathered}
F_{t} \equiv \mathbb{E}_{t} \sum_{T=t}^{\infty}(\beta \phi)^{T-t} f_{t, T}, \\
K_{t} \equiv \mathbb{E}_{t} \sum_{T=t}^{\infty}(\beta \phi)^{T-t} k_{t, T}, \\
f_{t, T} \equiv \frac{Y_{T}^{1-v}}{\exp \left(\mu_{T}\right)} R_{t, T}^{1-\sigma}, \\
k_{t, T} \equiv \frac{Y_{T}^{1-v}\left(1+i_{T}\right) \exp \left(u_{T}\right)}{R_{T}} R_{t, T}^{-\sigma},
\end{gathered}
$$

and

$$
R_{t, T} \equiv\left(\frac{R_{t}}{R_{T}}\right)
$$

Second order approximation leads to

$$
\begin{aligned}
F\left(\hat{F}_{t}+\frac{1}{2} \hat{F}_{t}^{2}\right) & =\mathbb{E}_{t} \sum_{T=t}^{\infty}(\beta \phi)^{T-t} f\left(\hat{f}_{T}+\frac{1}{2} \hat{f}_{T}^{2}\right) \\
\hat{F}_{t}+\frac{1}{2} \hat{F}_{t}^{2} & =(1-\beta \phi) \mathbb{E}_{t} \sum_{T=t}^{\infty}(\beta \phi)^{T-t}\left(\hat{f}_{T}+\frac{1}{2} \hat{f}_{T}^{2}\right),
\end{aligned}
$$

and

$$
\hat{K}_{t}+\frac{1}{2} \hat{K}_{t}^{2}=(1-\beta \phi) \mathbb{E}_{t} \sum_{T=t}^{\infty}(\beta \phi)^{T-t}\left(\hat{k}_{T}+\frac{1}{2} \hat{k}_{T}^{2}\right) .
$$


Then, equation (97) can be transformed into

$$
\begin{aligned}
\hat{r}_{t}^{*}= & (1-\beta \phi) \mathbb{E}_{t} \sum_{T=t}^{\infty}(\beta \phi)^{T-t}\left(\hat{k}_{t, T}-\hat{f}_{t, T}\right) \\
& +\frac{1-\beta \phi}{2} \mathbb{E}_{t} \sum_{T=t}^{\infty}(\beta \phi)^{T-t}\left(\hat{k}_{t, T}+\hat{f}_{t, T}\right)\left(\hat{k}_{t, T}-\hat{f}_{t, T}\right) \\
& -\frac{1-\beta \phi}{2} \hat{r}_{t}^{*} \mathbb{E}_{t} \sum_{T=t}^{\infty}(\beta \phi)^{T-t}\left(\hat{k}_{t, T}+\hat{f}_{t, T}\right)
\end{aligned}
$$

This is because

$$
\frac{1}{2}\left(\hat{F}_{t}-\hat{K}_{t}\right)\left(\hat{F}_{t}+\hat{K}_{t}\right)=-\frac{1-\beta \phi}{2} \hat{r}_{t}^{*} \mathbb{E}_{t} \sum_{T=t}^{\infty}(\beta \phi)^{T-t}\left(\hat{f}_{T}+\hat{k}_{T}\right),
$$

where the higher order terms are ignored.

Equations (98) and (99) are expressed in log exact form as

$$
f_{t, T} \equiv(1-v) \hat{Y}_{T}-\mu_{T}+(1-\sigma) \hat{R}_{t, T},
$$

and

$$
k_{t, T}=(1-v) \hat{Y}_{T}+i_{T}+u_{T}-\hat{R}_{T}-\sigma \hat{R}_{t, T} .
$$

Thus,

$$
\begin{aligned}
\hat{k}_{t, T}-\hat{f}_{t, T} & =i_{T}+\mu_{T}-\hat{R}_{T}-\hat{R}_{t, T} \\
& \equiv \bar{z}_{T}-\hat{R}_{t, T}
\end{aligned}
$$

and

$$
\begin{aligned}
\hat{k}_{t, T}+\hat{f}_{t, T} & =2(1-v) \hat{Y}_{T}+i_{T}-\hat{\mu}_{T}-\hat{R}_{T}+(1-2 \sigma) \hat{R}_{t, T} \\
& \equiv \bar{x}_{T}+(1-2 \sigma) \hat{R}_{t, T} .
\end{aligned}
$$

Then, equation (100) further collapses to

$$
\begin{aligned}
\hat{r}_{t}^{*}= & -\frac{1-\beta \phi}{2} \hat{r}_{t}^{*} Z_{t}+(1-\beta \phi) \mathbb{E}_{t} \sum_{T=t}^{\infty}(\beta \phi)^{T-t}\left(\bar{z}_{T}-\hat{R}_{t, T}\right) \\
& +\frac{1-\beta \phi}{2} \mathbb{E}_{t} \sum_{T=t}^{\infty}(\beta \phi)^{T-t}\left[\bar{x}_{T}+(1-2 \sigma) \hat{R}_{t, T}\right]\left(\bar{z}_{T}-\hat{R}_{t, T}\right) .
\end{aligned}
$$


where

$$
Z_{t} \equiv \mathbb{E}_{t} \sum_{T=t}^{\infty}(\beta \phi)^{T-t}\left[\bar{x}_{T}+(1-2 \sigma) \hat{R}_{t, T}\right]
$$

With equations:

$$
\begin{aligned}
& \frac{\beta \phi \hat{r}_{t+1}^{*}}{1-\beta \phi}=-\frac{\beta \phi}{2} \hat{r}_{t+1}^{*} Z_{t+1}+\beta \phi \mathbb{E}_{t} \sum_{T=t+1}^{\infty}(\beta \phi)^{T-(t+1)}\left(\bar{z}_{T}-\hat{R}_{t+1, T}\right) \\
&+\frac{\beta \phi}{2} \mathbb{E}_{t} \sum_{T=t+1}^{\infty}(\beta \phi)^{T-(t+1)}\left[\bar{x}_{T} \bar{z}_{T}-\bar{x}_{T} \hat{R}_{t+1, T}+(1-2 \sigma) \hat{R}_{t+1, T} \bar{z}_{T}-(1-2 \sigma) \hat{R}_{t+1, T}^{2}\right], \\
& \hat{k}_{t+1, T}-\hat{f}_{t+1, T}=\bar{z}_{T}-\hat{R}_{t+1, T},
\end{aligned}
$$

and

$$
\hat{r}_{t+1}^{*}=\hat{K}_{t+1}-\hat{F}_{t+1}=\mathbb{E}_{t} \sum_{T=t+1}^{\infty}(\beta \phi)^{T-(t+1)}\left(\bar{z}_{T}-\hat{R}_{t+1, T}\right),
$$

Equation (101) is further transformed into

$$
\begin{aligned}
\frac{\hat{r}_{t}^{*}}{1-\beta \phi}= & \bar{z}_{t}+\mathbb{E}_{t} \frac{\beta \phi\left(\hat{r}_{t+1}^{*}+\hat{R}_{t+1, t}\right)}{1-\beta \phi}+\frac{\bar{x}_{t} \bar{z}_{t}}{2} \\
& -\frac{\hat{r}_{t}^{*} Z_{t}}{2}+\mathbb{E}_{t} \frac{\beta \phi Z_{t+1}\left(\hat{r}_{t+1}^{*}+\hat{R}_{t+1, t}\right)}{2} \\
& -\mathbb{E}_{t} \frac{\beta \phi(1-2 \sigma) \hat{r}_{t+1}^{*} \hat{R}_{t+1, t}}{2(1-\beta \phi)}-\mathbb{E}_{t} \frac{\beta \phi(1-2 \sigma) \hat{R}_{t+1, t}^{2}}{2(1-\beta \phi)} .
\end{aligned}
$$

Second order approximation of equations (81) and (96) leads to

$$
r_{t}^{*} \approx \frac{\phi \hat{R}_{t, t-1}}{1-\phi}-\frac{(1-\sigma) \phi \hat{R}_{t, t-1}^{2}}{2(1-\phi)^{2}} .
$$

Substitution of the approximated equation (104) into (103) results in

$$
\begin{aligned}
& \hat{R}_{t, t-1}-\frac{(1-\sigma) \hat{R}_{t, t-1}^{2}}{2(1-\phi)}+\frac{(1-\beta \phi) \hat{R}_{t, t-1} Z_{t}}{2}+\frac{\sigma \hat{R}_{t, t-1}^{2}}{2} \\
= & \frac{(1-\beta \phi)(1-\phi)}{\phi} \mathbb{E}_{t} \sum_{T=t}^{\infty} \beta^{T-t} \bar{z}_{T} \\
& +\frac{(1-\beta \phi)(1-\phi)}{2 \phi} \mathbb{E}_{t} \sum_{T=t}^{\infty} \beta^{T-t} \bar{x}_{T} \bar{z}_{T} \\
& +\frac{\sigma}{2} \mathbb{E}_{t} \sum_{T=t}^{\infty} \beta^{T-t} \hat{R}_{T, T-1}^{2}
\end{aligned}
$$


On the other hand, $Z_{t}$ in (102) can be expressed recursively as

$$
Z_{t}=\bar{x}_{t}+\mathbb{E}_{t} \frac{\beta \phi(1-2 \sigma) \hat{R}_{t+1, t}}{1-\beta \phi}+\beta \phi Z_{t+1} .
$$

Finally, solving equations (105) and (106) at time 0 leads to

$$
\begin{aligned}
& \bar{K}_{0}=\frac{(1-\beta \phi)(1-\phi)}{\phi} \mathbb{E}_{t} \sum_{t=0}^{\infty} \beta^{t}\left(i_{t}+\mu_{t}+u_{t}-\hat{R}_{t}\right) \\
& +\frac{(1-\beta \phi)(1-\phi)}{2 \phi} \mathbb{E}_{t} \sum_{t=0}^{\infty} \beta^{t}\left(2 \hat{z}_{t}+2(1-v) \hat{Y}_{t}+i_{t}-\hat{\mu}_{t}-\hat{R}_{t}\right)\left(i_{t}+\mu_{t}+u_{t}-\hat{R}_{t}\right) \\
& +\frac{\sigma}{2} \mathbb{E}_{t} \sum_{t=0}^{\infty} \beta^{t}\left(\hat{R}_{t}-\hat{R}_{t-1}\right)^{2},
\end{aligned}
$$

where

$$
\bar{K}_{0}=\hat{R}_{0,-1}-\frac{(1-\sigma) \hat{R}_{0,-1}^{2}}{2(1-\phi)}+\frac{(1-\beta \phi) \hat{R}_{0,0-1} Z_{0}}{2}+\frac{\sigma \hat{R}_{0,0-1}^{2}}{2}
$$

Thus,

$$
\begin{aligned}
& \mathbb{E}_{t} \sum_{t=0}^{\infty} \beta^{t}\left(i_{t}+\mu_{t}+u_{t}-\hat{R}_{t}\right) \\
\approx & \mathbb{E}_{t} \sum_{t=0}^{\infty} \beta^{t}\left\{\begin{array}{c}
-\left[(1-v) \hat{Y}_{t}\right]\left(i_{t}-\hat{\mu}_{t}-\hat{R}_{t}\right)-\frac{1}{2}\left(i_{t}+\mu_{t}-\hat{R}_{t}\right)^{2} \\
-\frac{\sigma \phi}{2(1-\beta \phi)(1-\phi)}\left(\hat{R}_{t}-\hat{R}_{t-1}\right)^{2}
\end{array}\right\} .
\end{aligned}
$$

